\title{
Bayesianisches Denken mit Dinosauriern
}

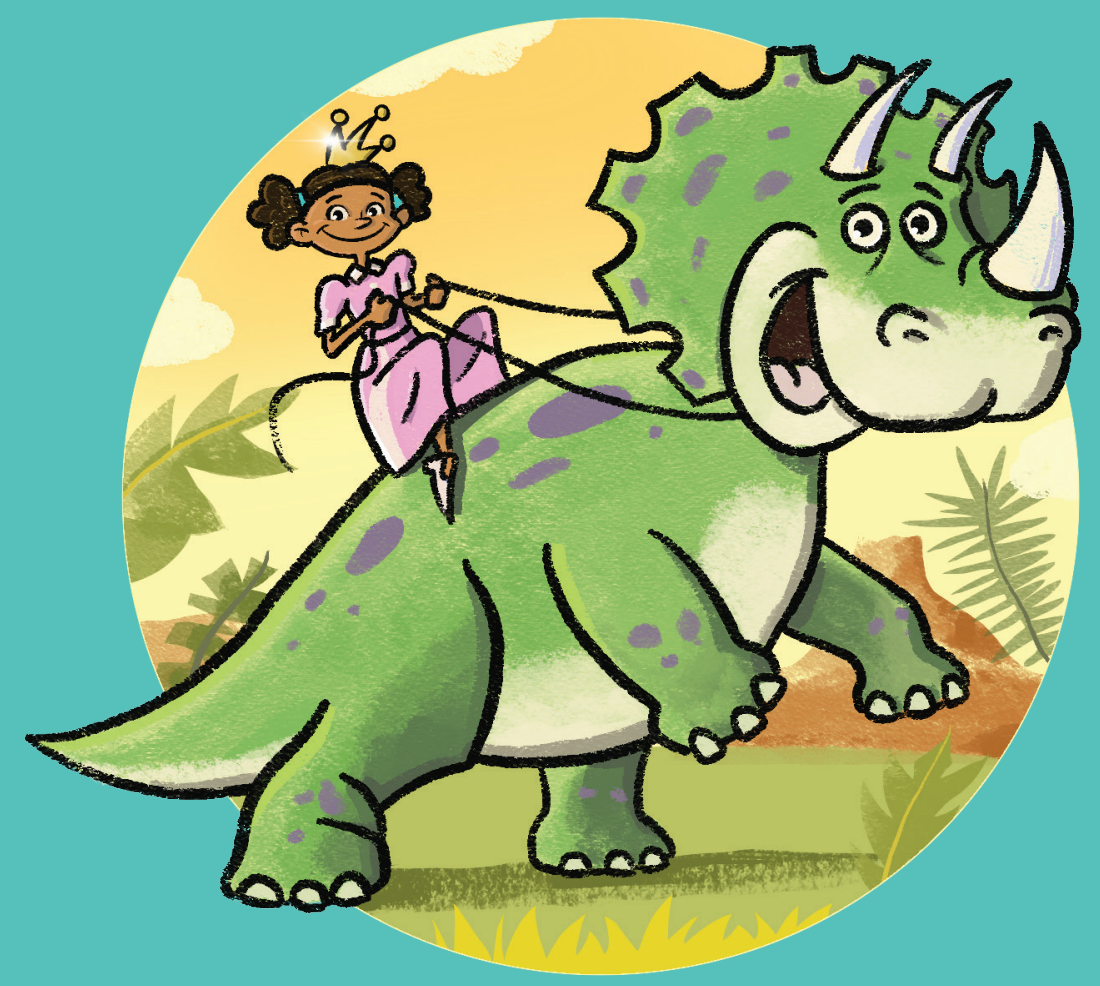

Eric-Jan Wagenmakers Illustriert von Viktor Beekman 


\section{Bayesianisches Denken mit Dinosauriern}

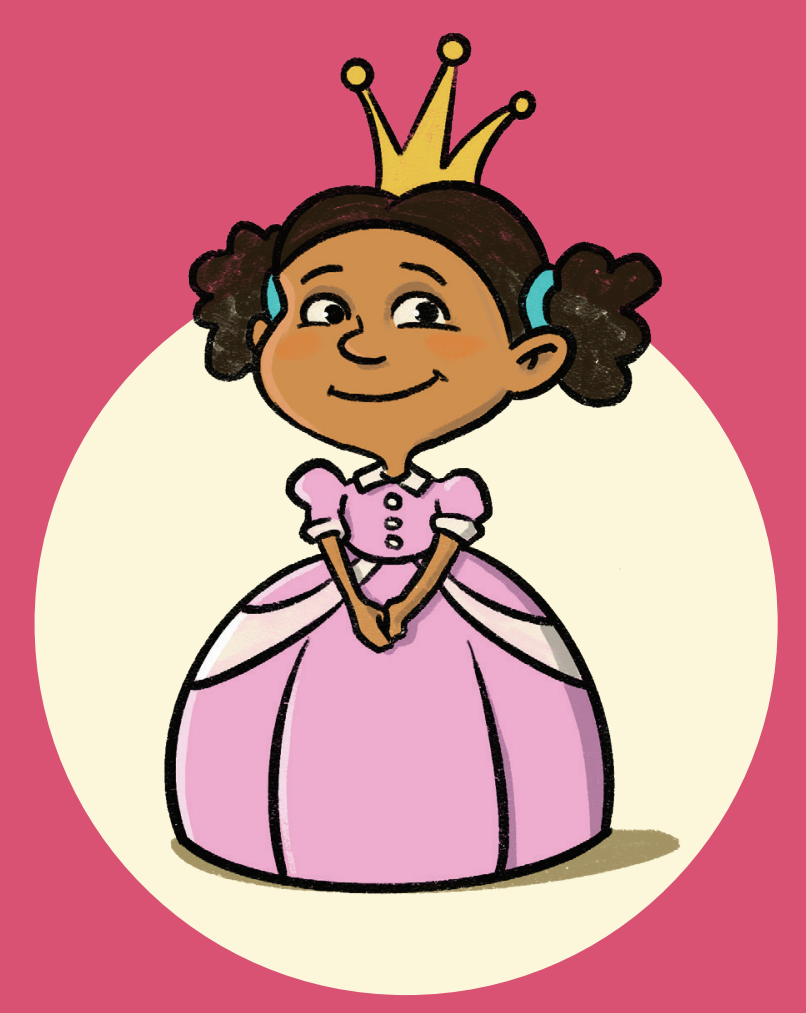

Für Theo und Leanne 
Es war einmal, in einem weit entfernten Land, dass Kati und Miruna darüber stritten wer mehr über Dinosaurier weiß...

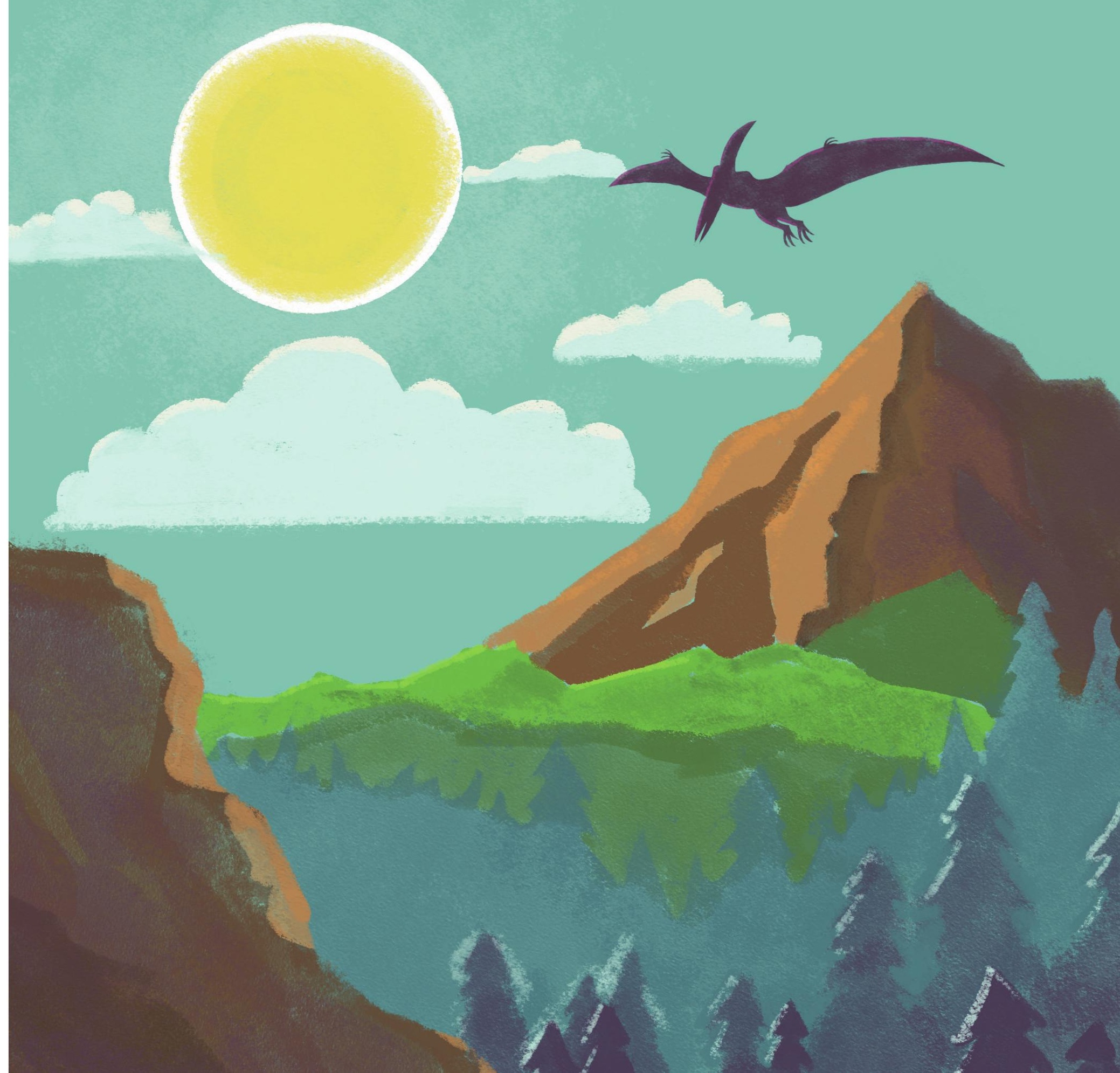




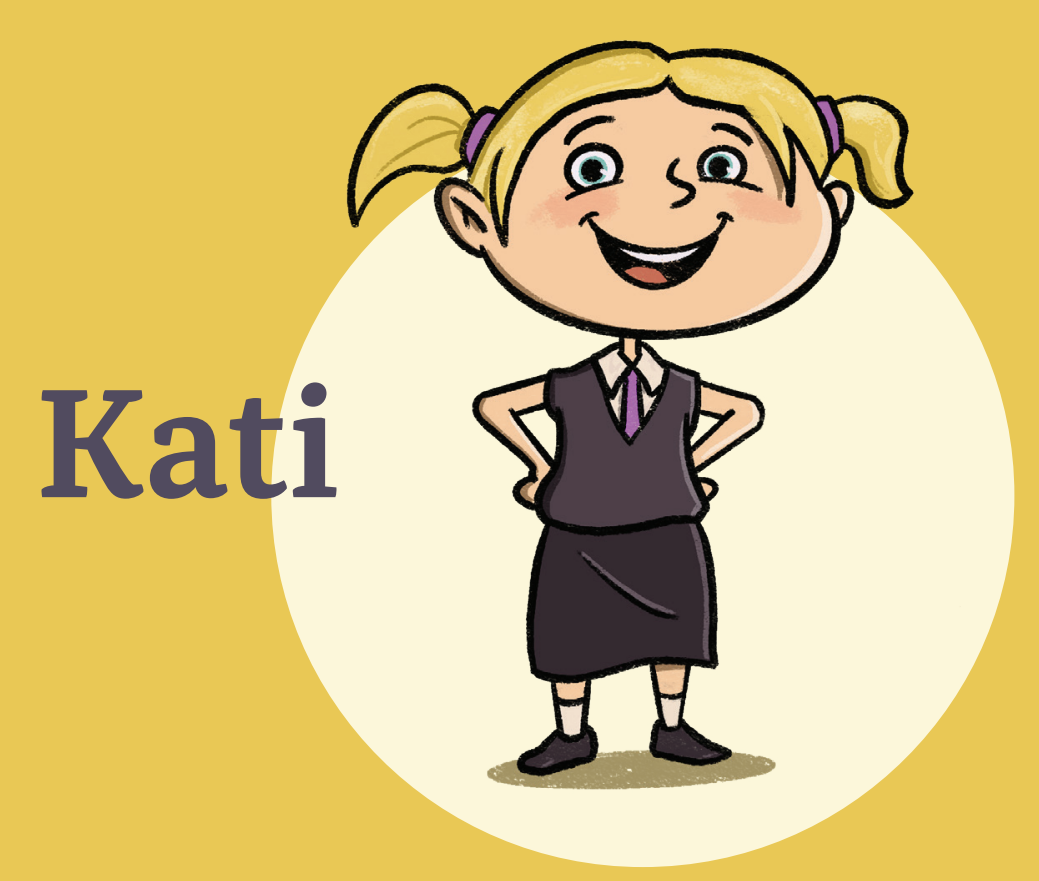

'Ich kenne alle Dinosauriernamen!

Und ich kann sehr schnell

"Huehuecanauhtlus" sagen.'

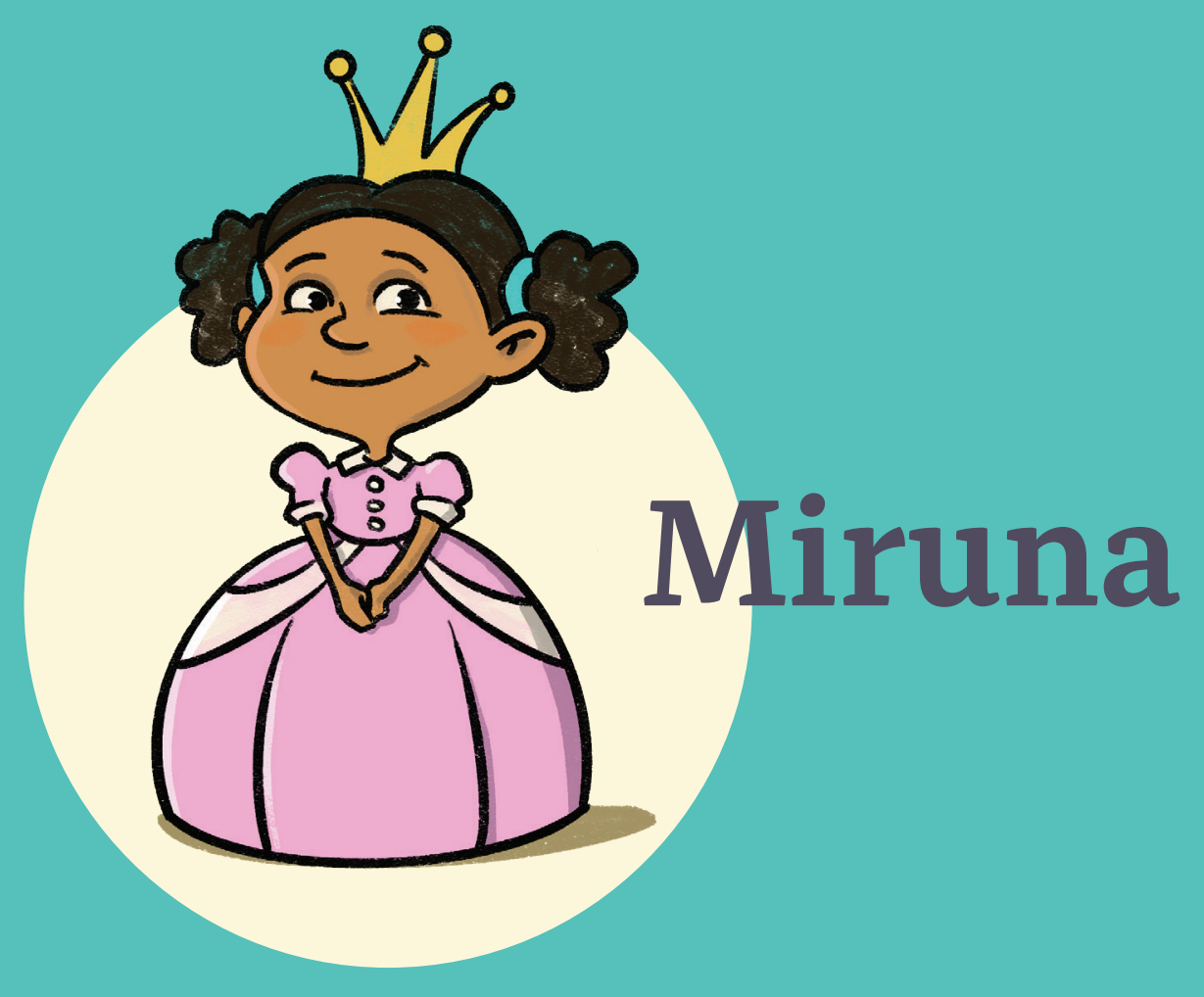

'Ich trage eine Krone! Außerdem schaue ich viel Fernsehen.

Und mein Papa kann mir so viele Dinosaurier kaufen wie ich will.' 
Wer mehr über Dinosaurier weiß, bekommt von Tante Agathe 14 selbstgebackene Kekse.

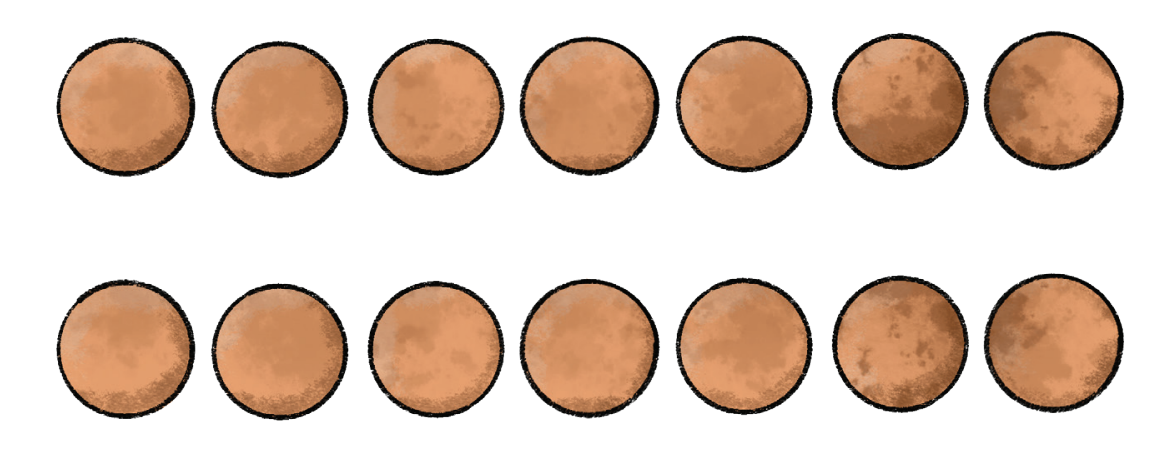


Tante Agathe ist sich nicht sicher, ob Kati oder Miruna am meisten über Dinosaurier weiß.

Deshalb denkt sie darüber nach, ob sie den beiden einfach gleich viele Kekse geben soll.
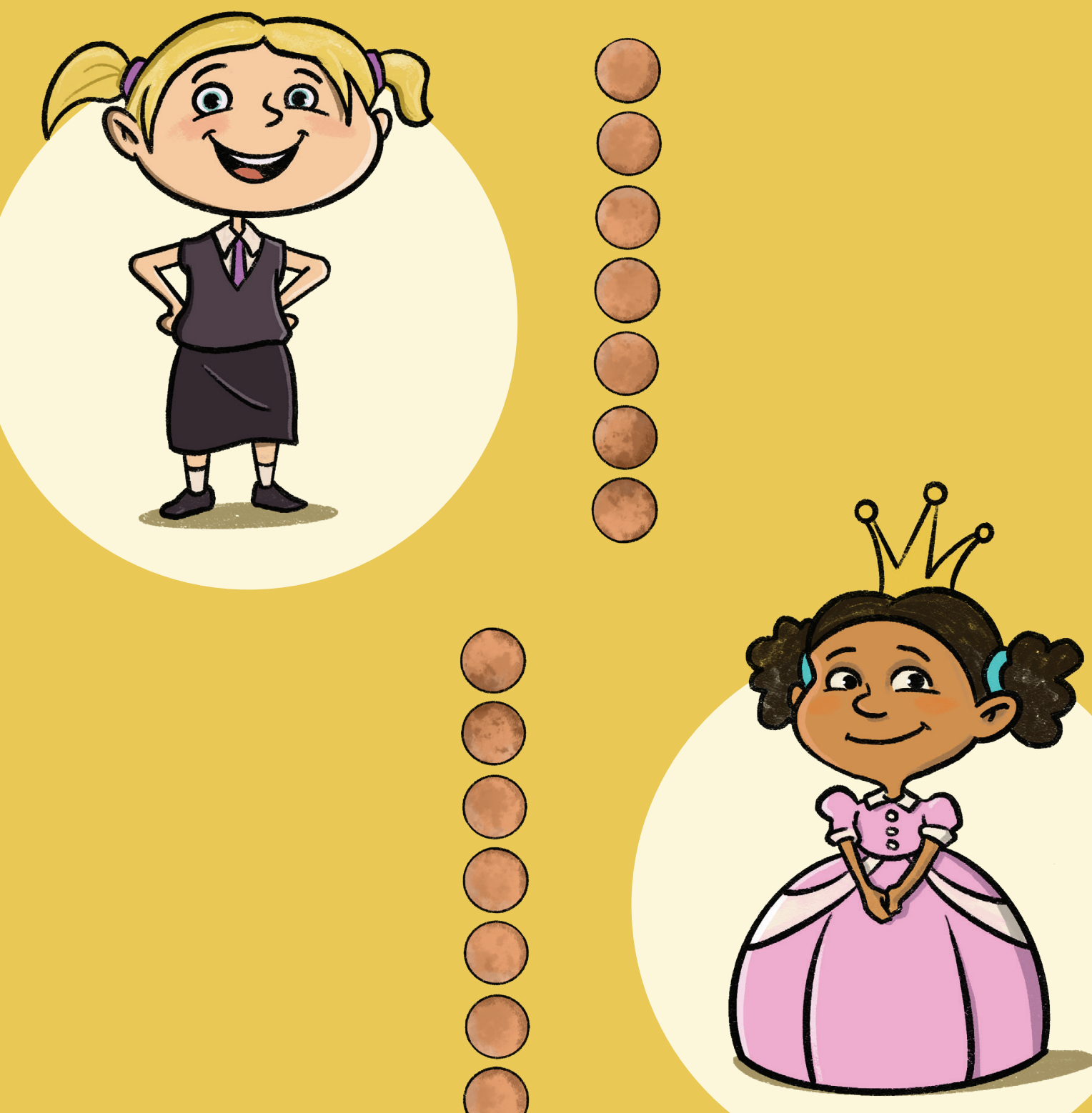
Aber Moment! Tante Agathe hat eine Idee. Sie wird den beiden eine Frage stellen, um so herauszufinden, wer mehr über Dinosaurier weiß.

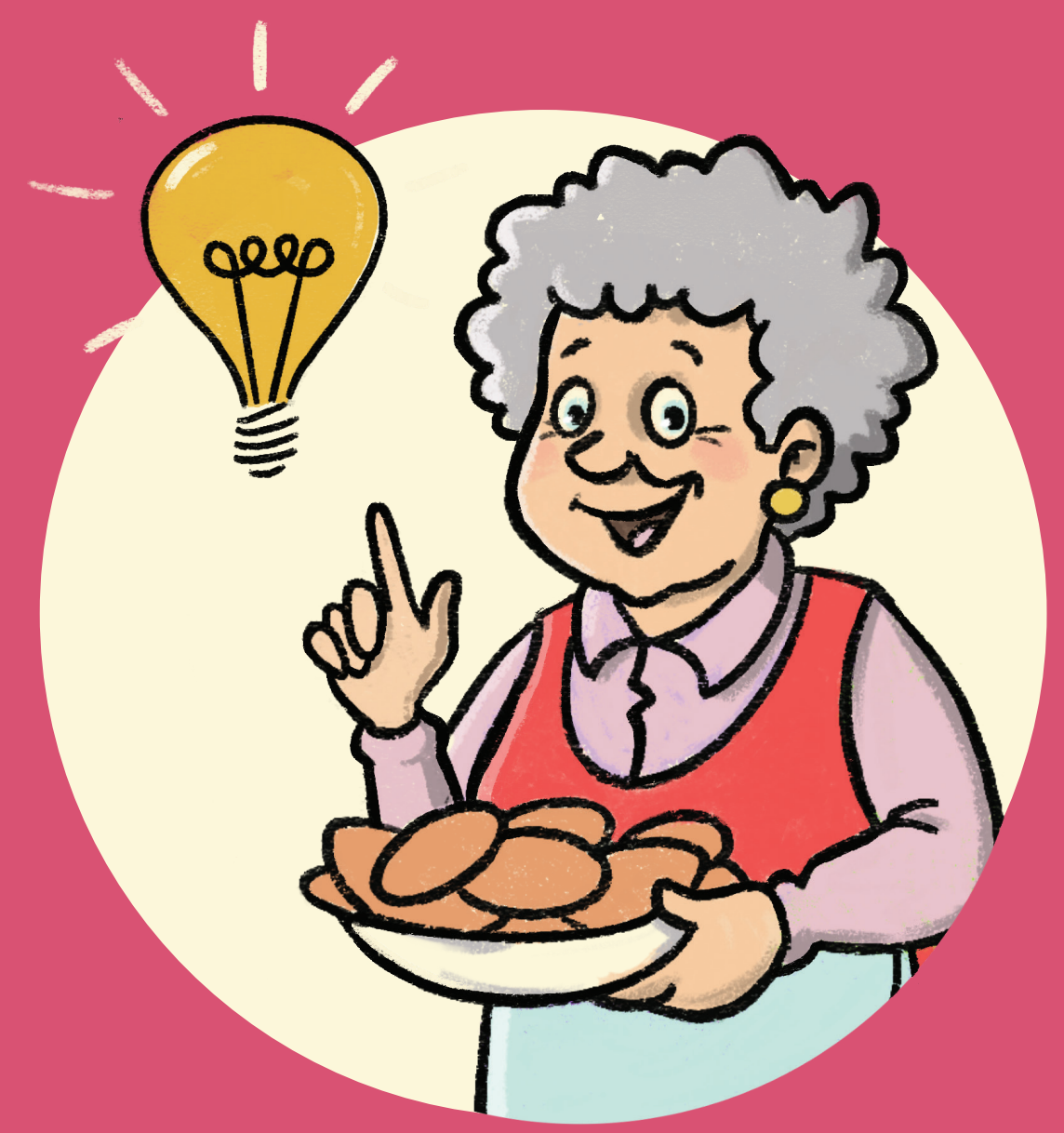




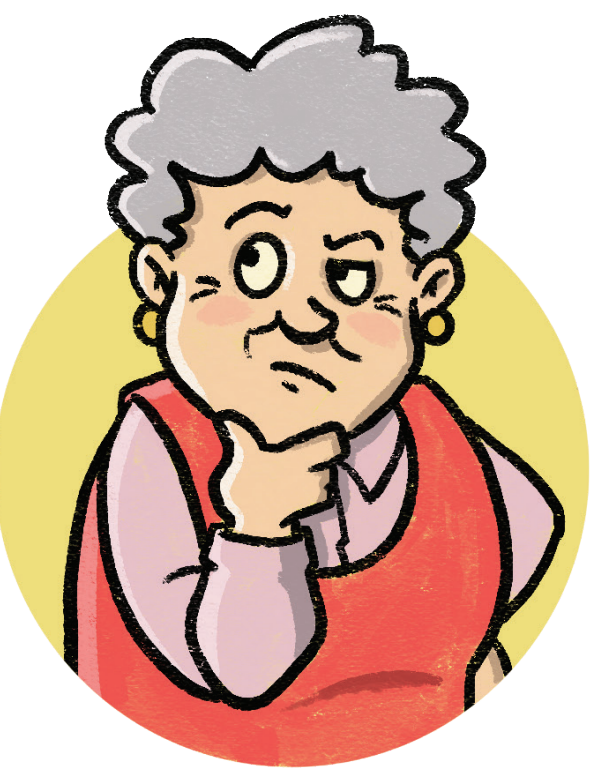

Die Frage lautet:

'Wie viele Hörner hat ein Triceratops auf seinem Kopf?'

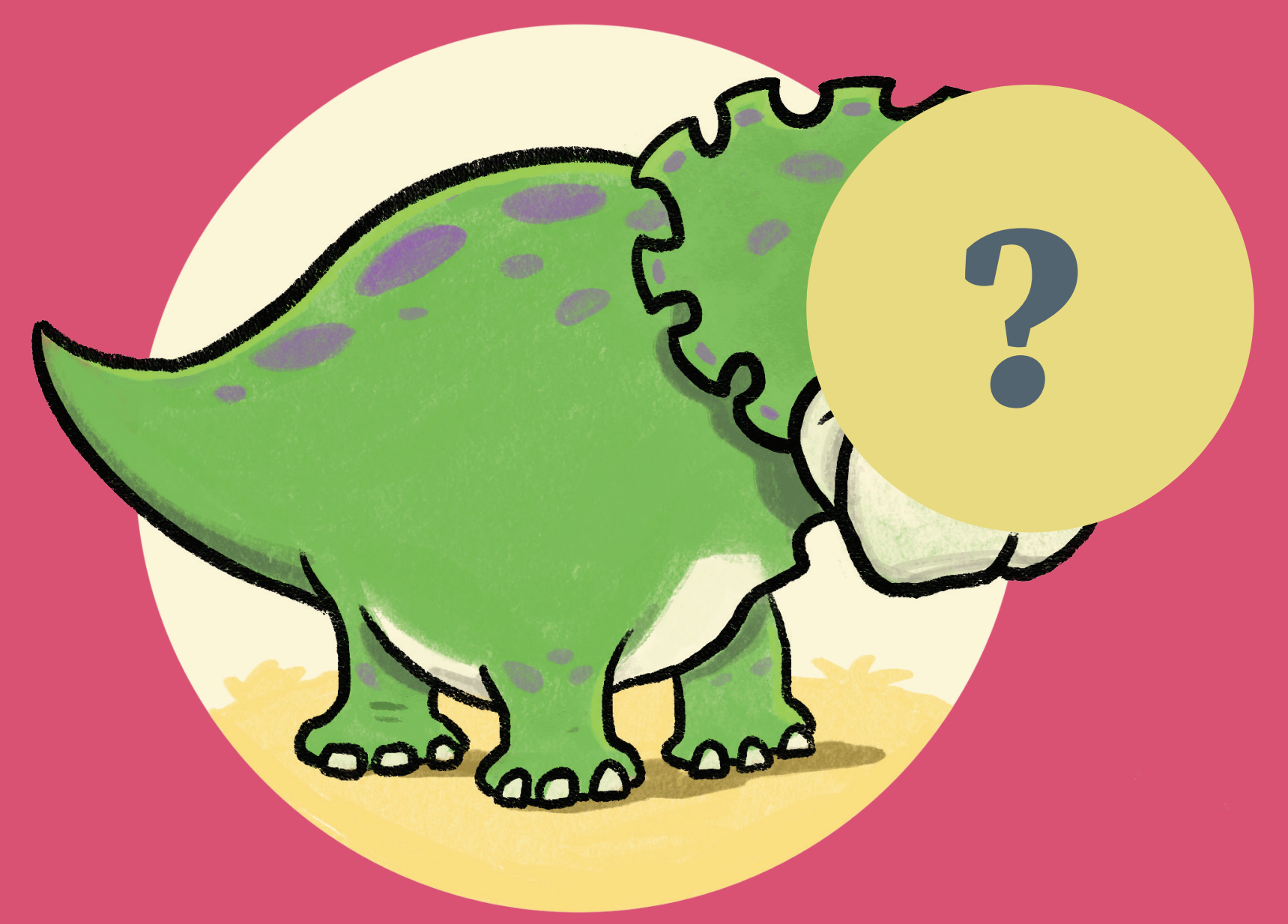

$-15-$ 


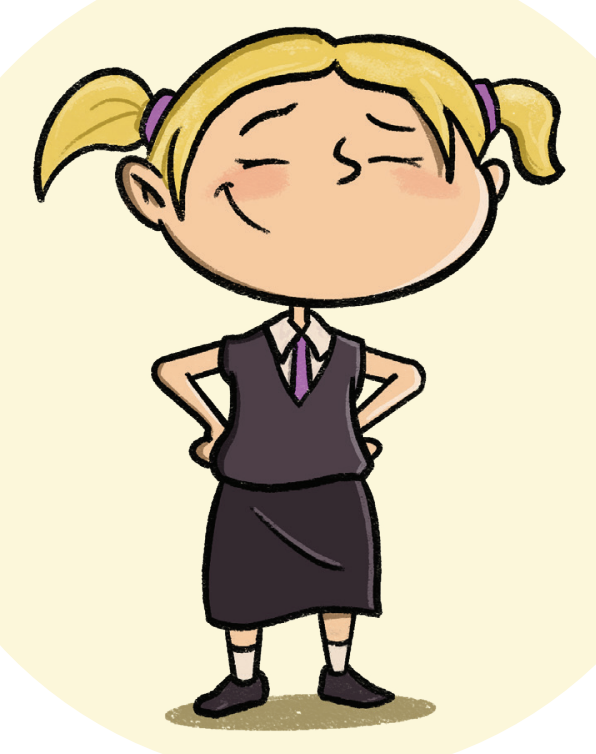

'Drei! Ich bin mir ganz sicher!'

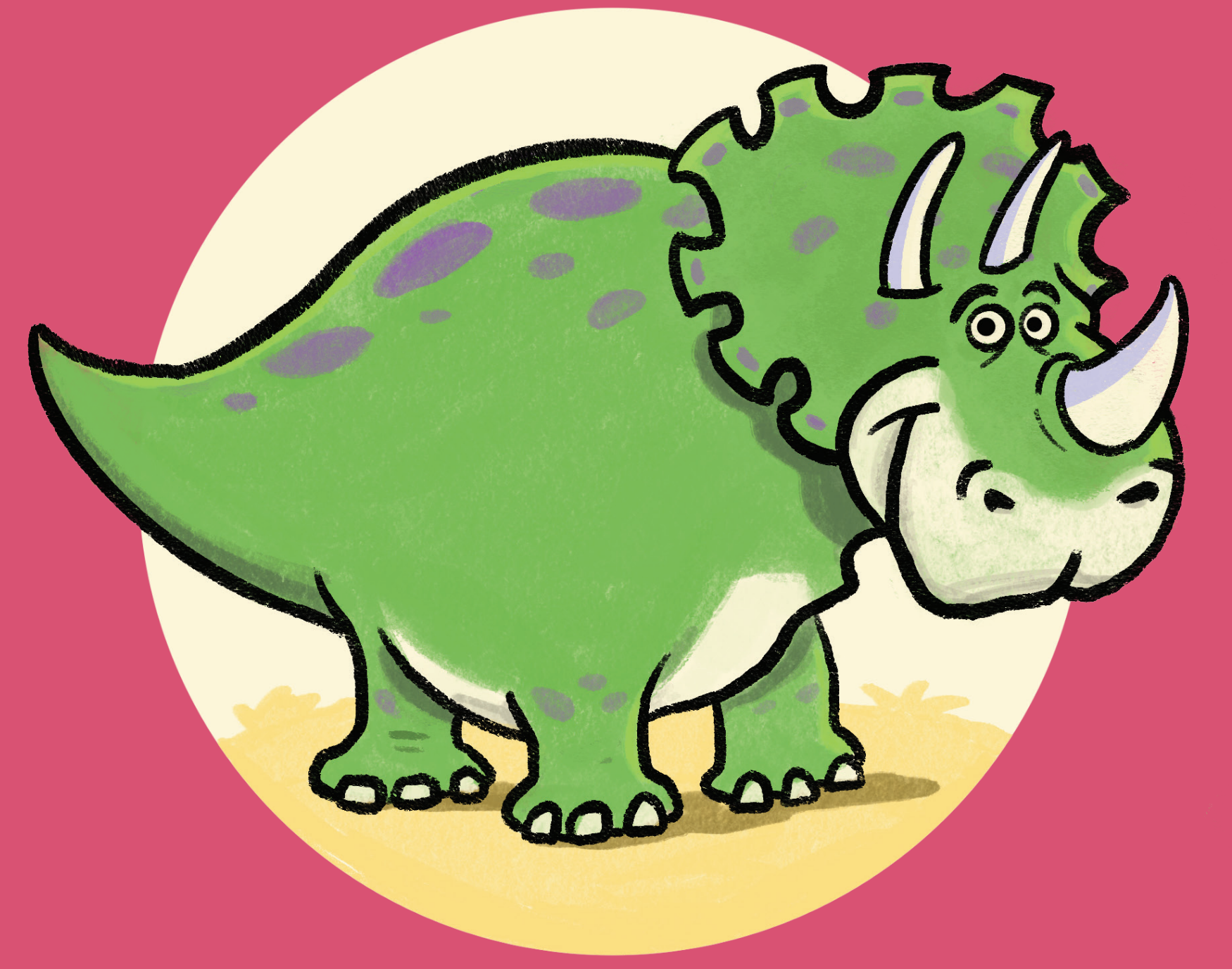

$-17-$ 


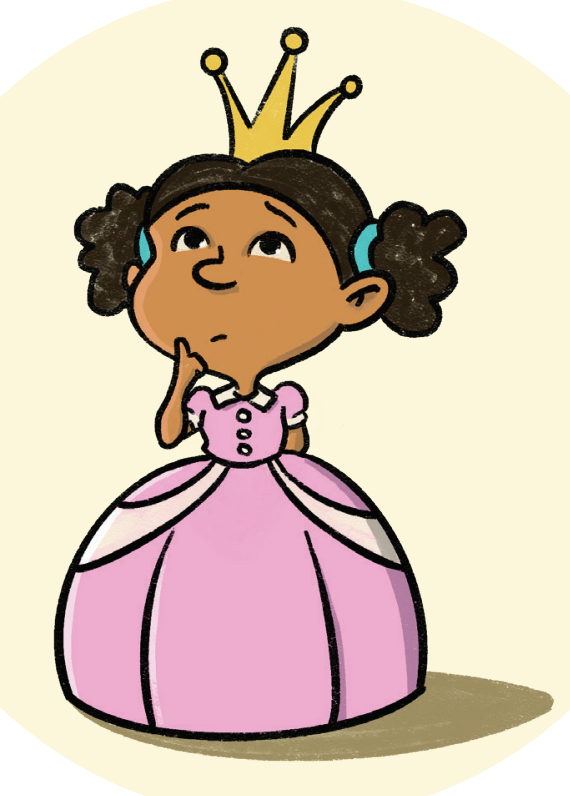

'Ohje, das ist schwierig! Ich bin mir nicht sicher. Es könnte keines sein, oder eins, oder zwei, oder drei, oder vier, oder fünf - jede dieser Möglichkeiten ist für mich gleich wahrscheinlich!'

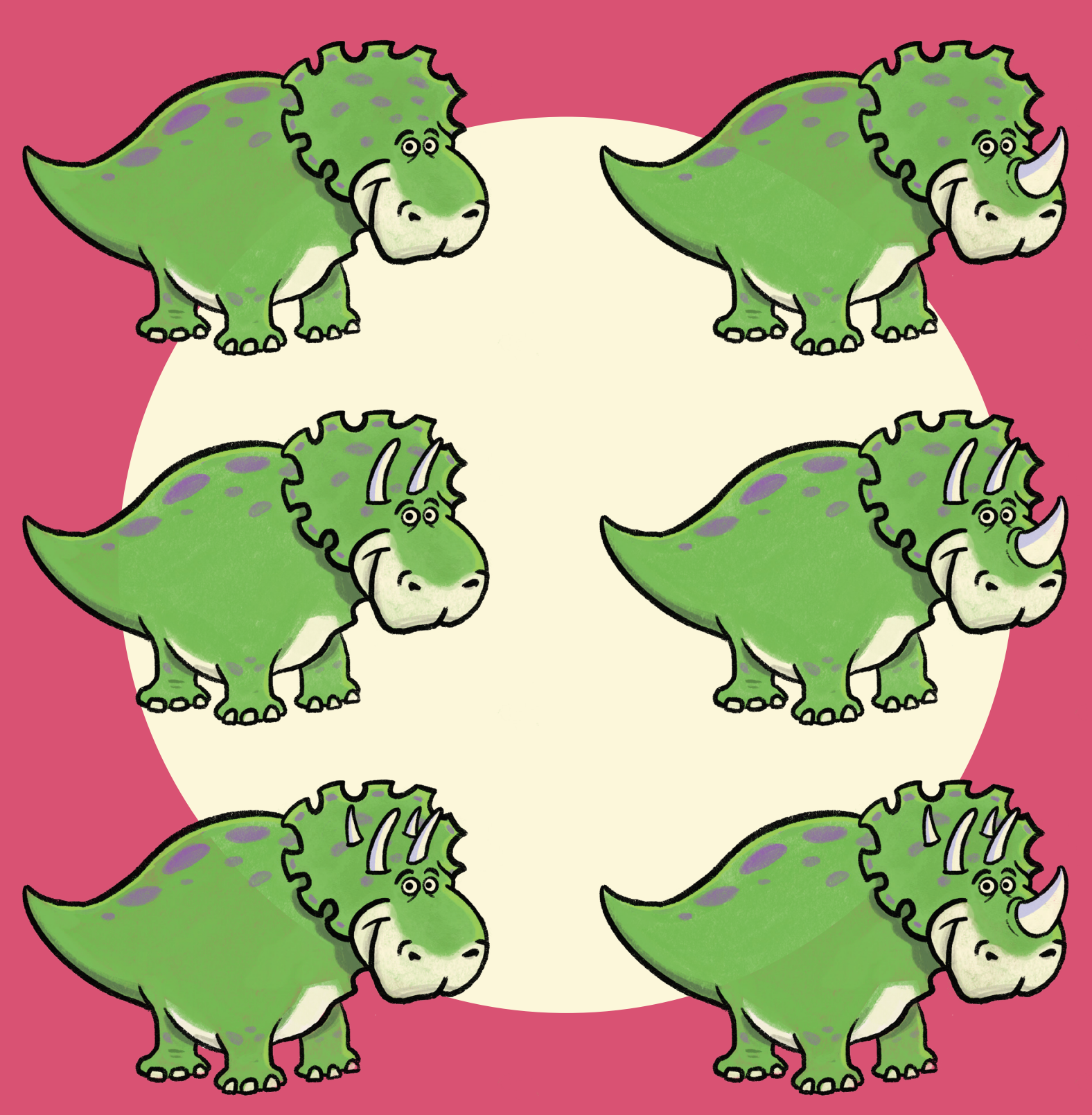

$-19-$ 


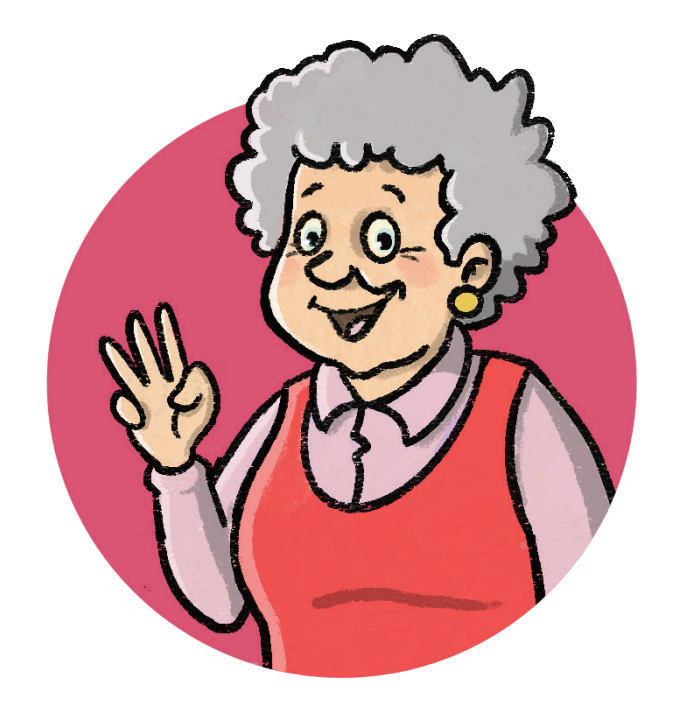

'Die richtige Antwort lautet drei. Ein Triceratops hat drei Hörner auf seinem Kopf.'

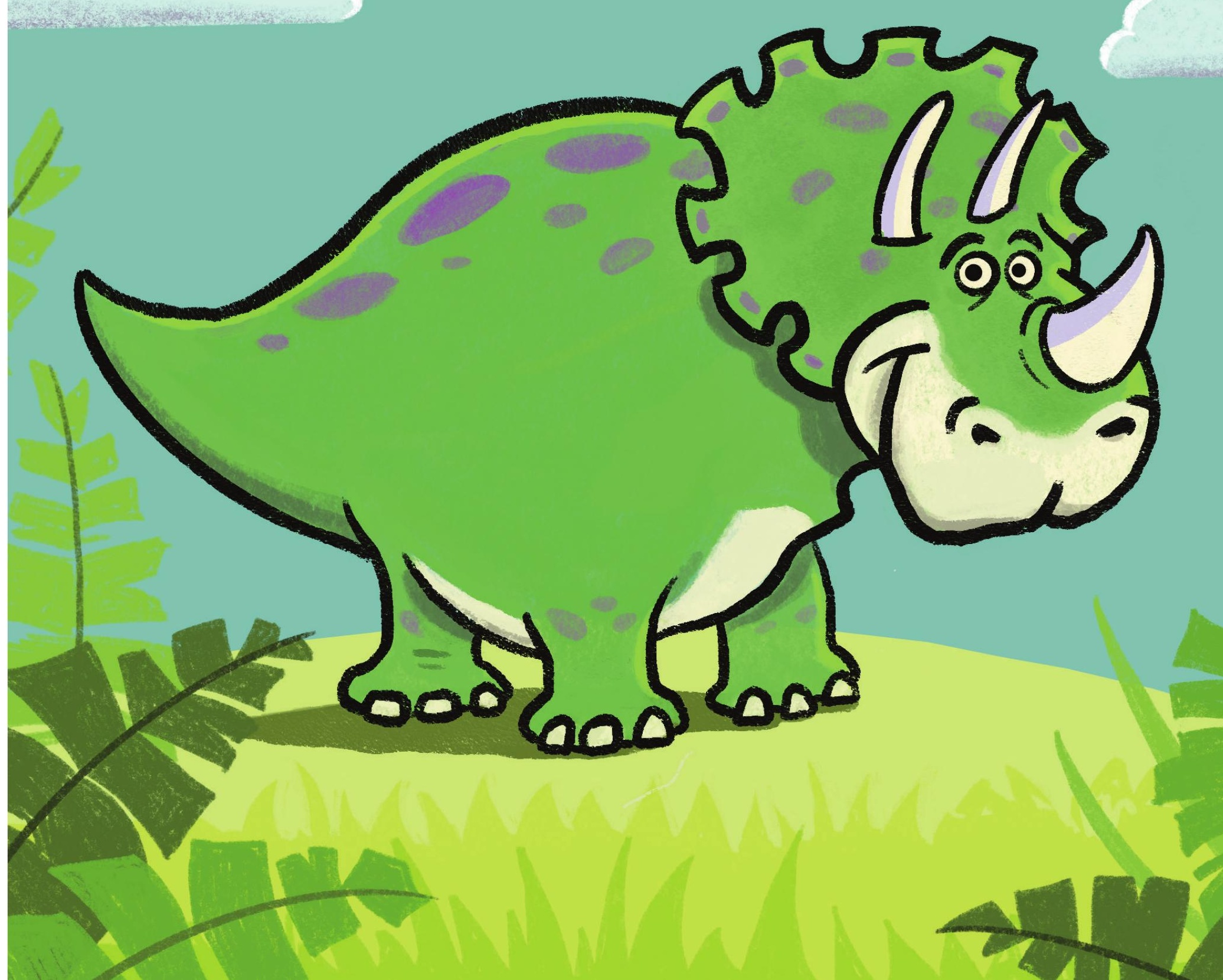


Wie gut konnten Kati und Miruna die richtige Antwort vorhersagen?

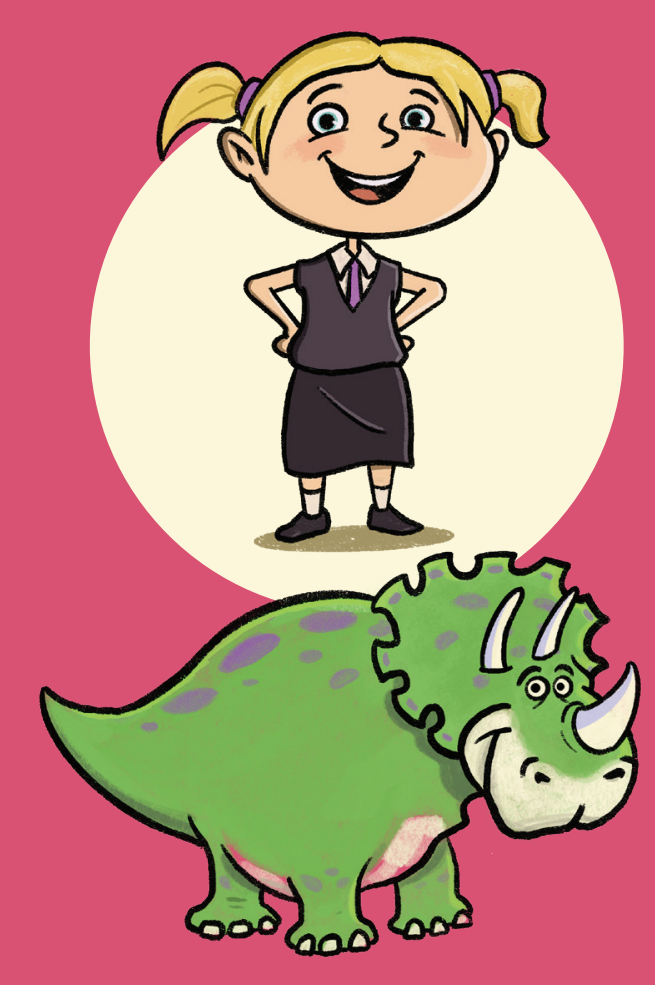

Völlig richtig!

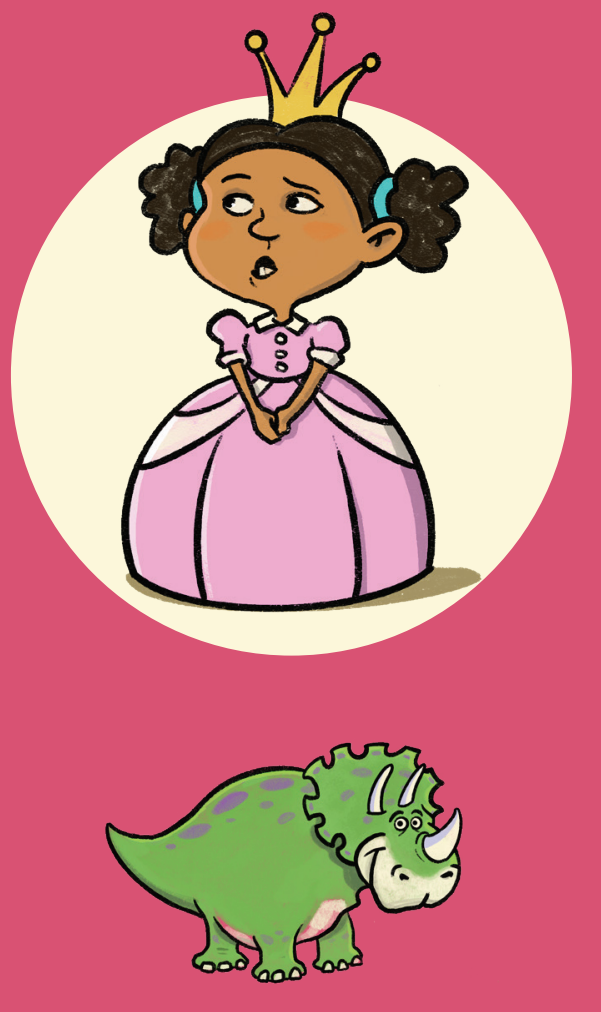

Eine von sechs ihrer Vorhersagen war richtig!
Kati war sechsmal besser im

Vorhersagen als Miruna. Deshalb denkt Tante Agathe nun darüber nach, Kati sechsmal so viele Kekse zu geben wie Miruna.
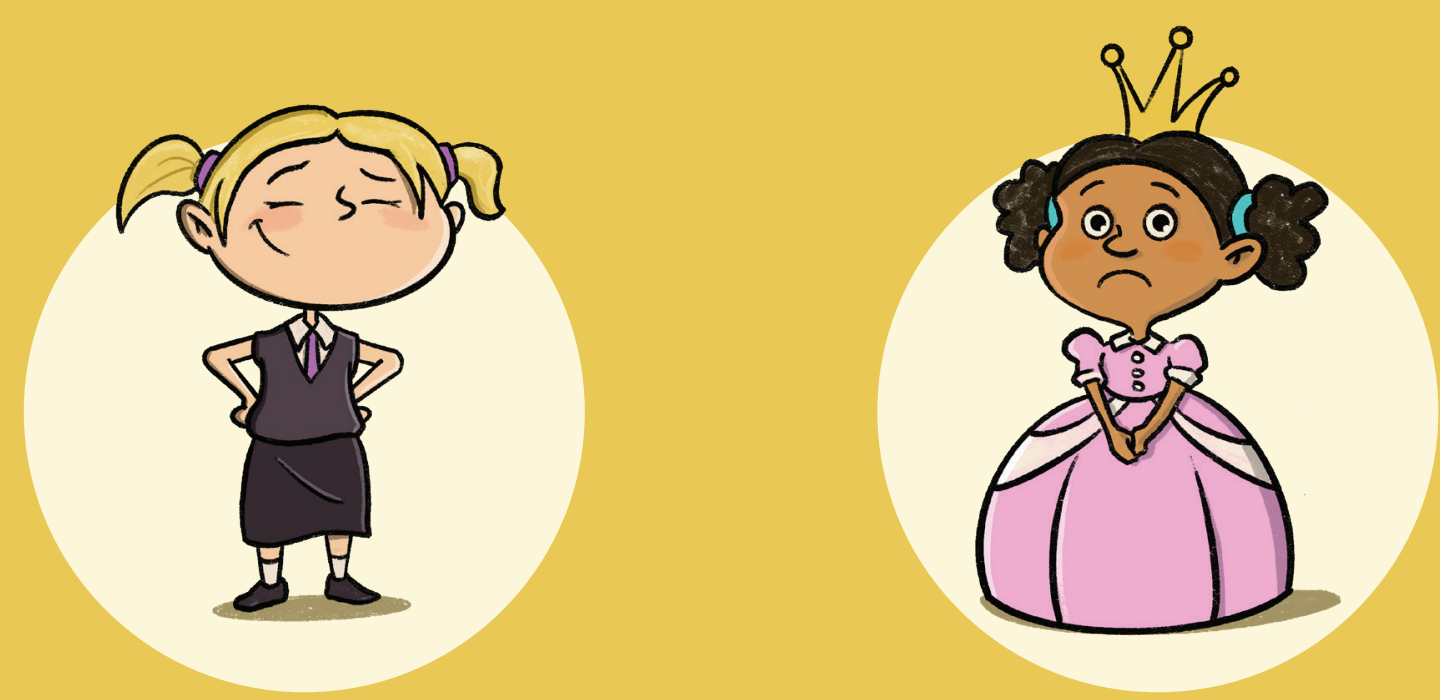

000000 
Aber Moment! Tante Agathe hat noch eine Idee. Sie wird den beiden noch eine zweite Frage über Dinosaurier stellen. Seid ihr bereit?

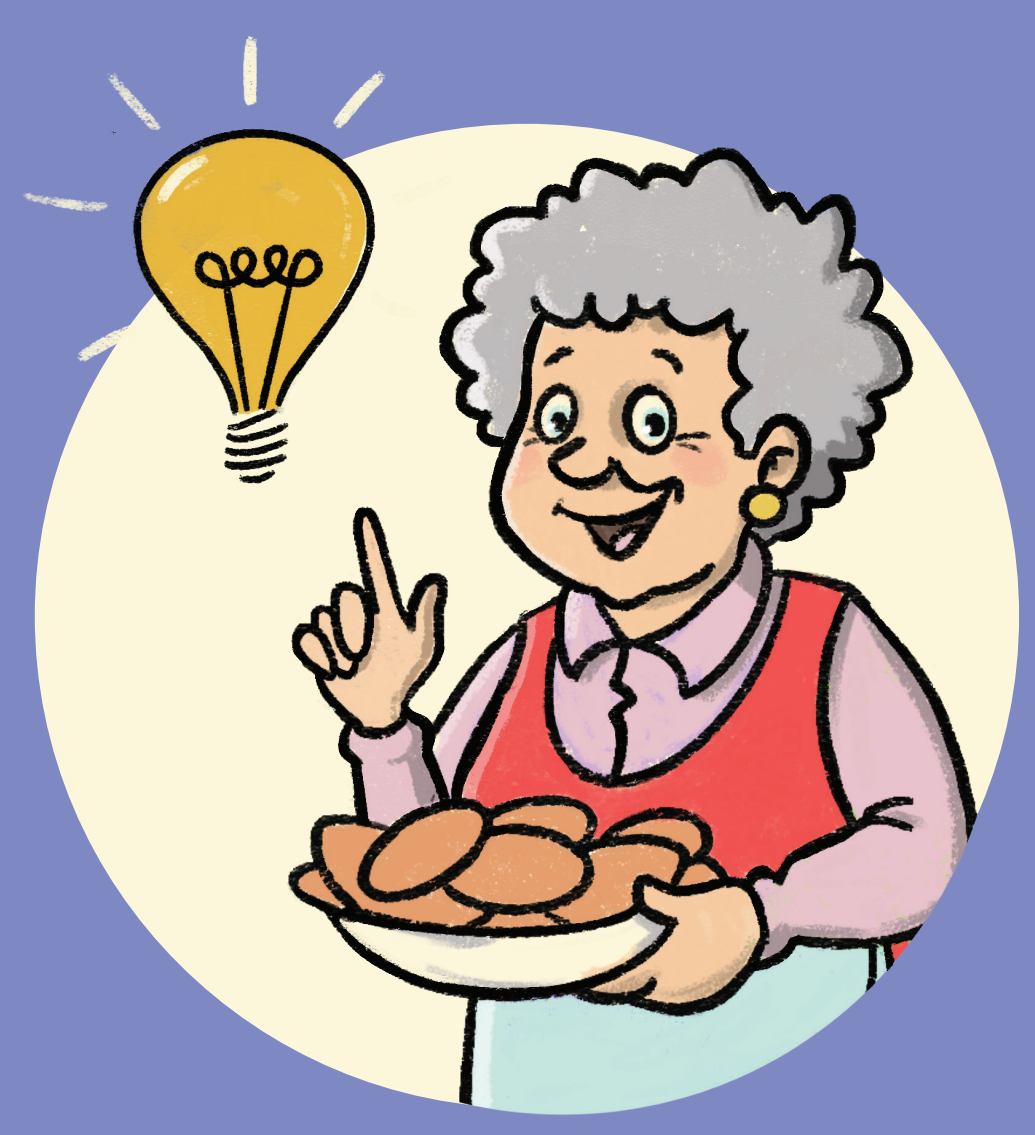




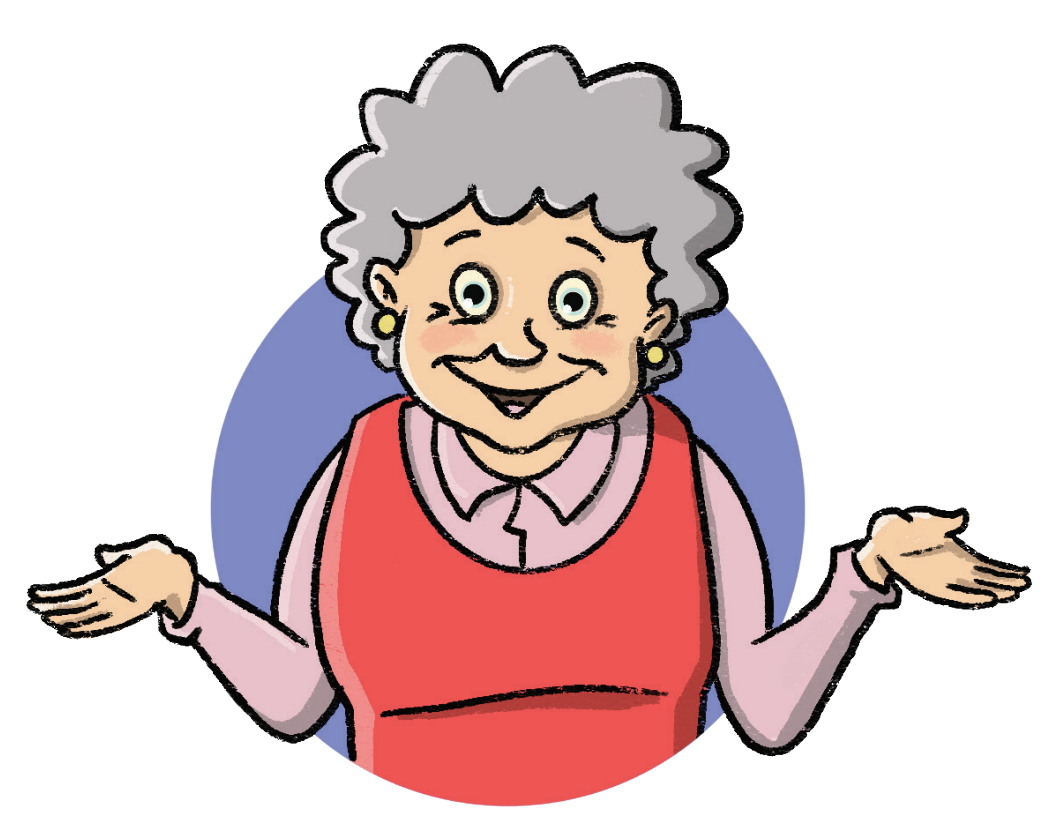

Die zweite Frage lautet:

'Wie viele Stacheln hat ein

Stegosaurus an seinem Schwanz?'

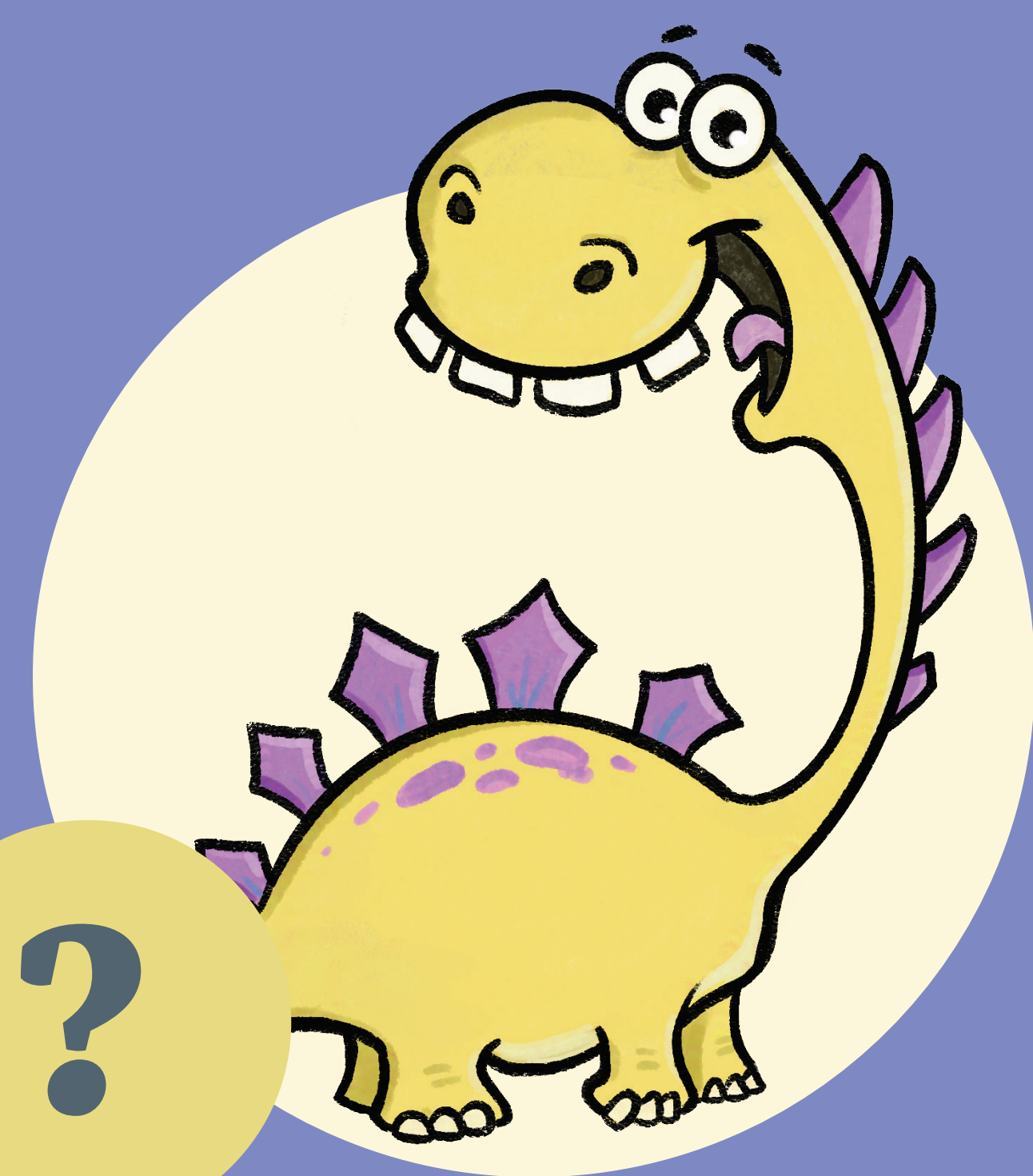

$-27-$ 


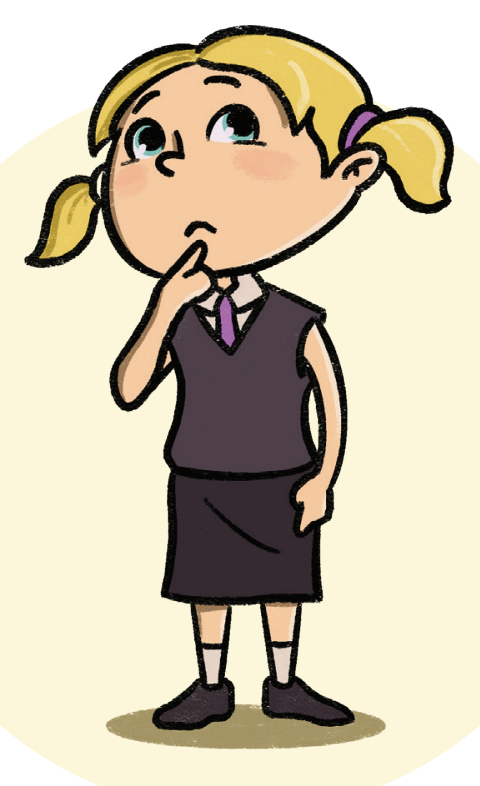

'Hmmm. Ich bin mir nicht sicher. Vier oder sechs Stacheln - beide Möglichkeiten kommen mir gleich wahrscheinlich vor.'

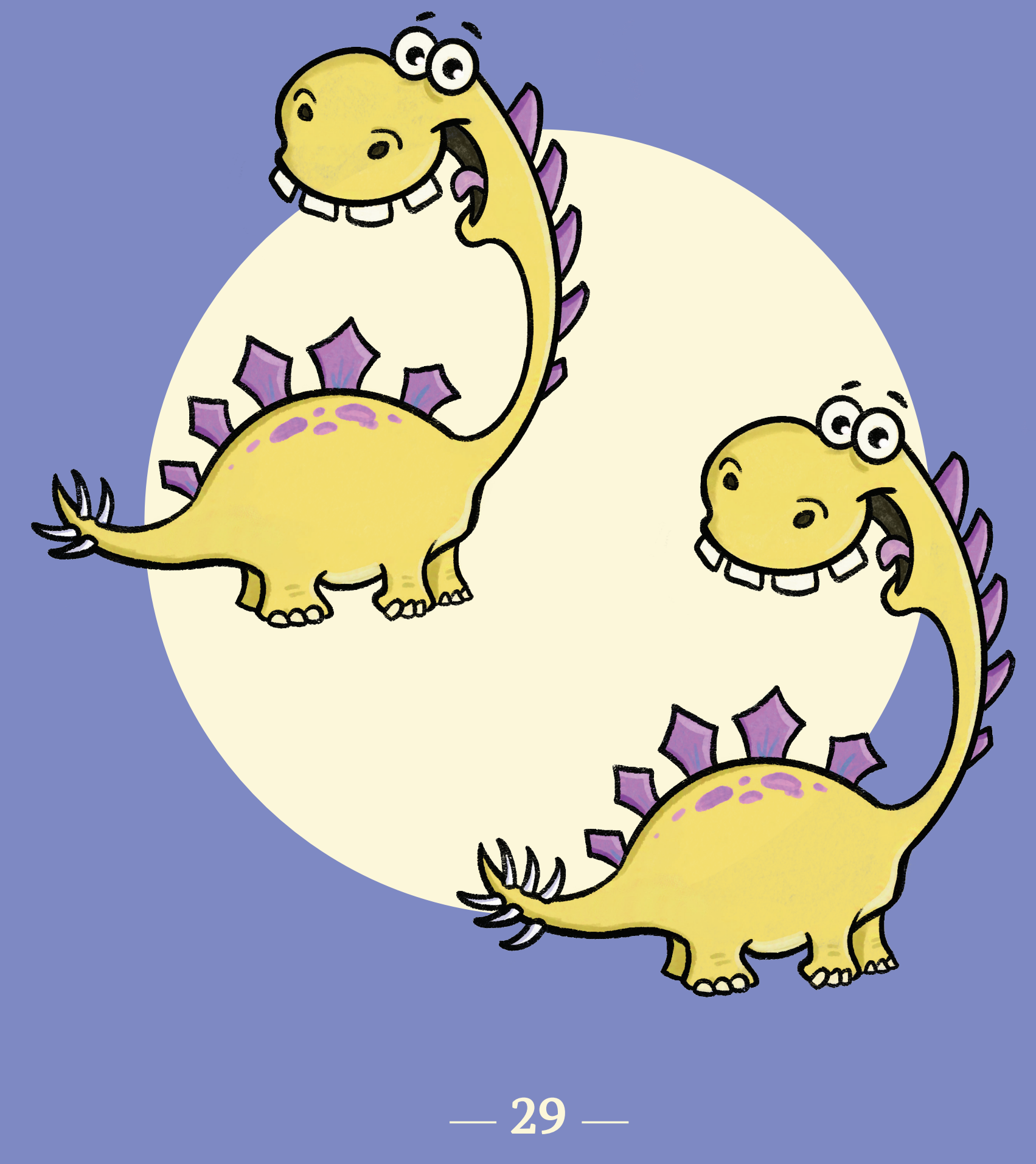




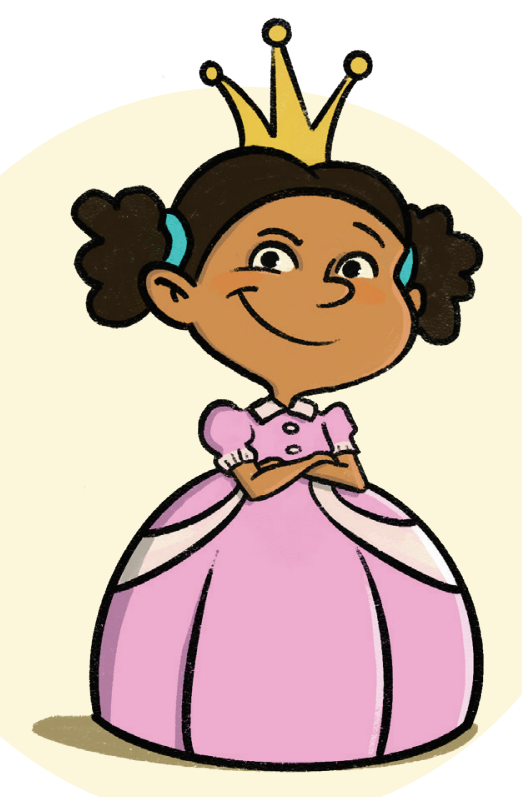

'Vier! Daran besteht kein Zweifel!'

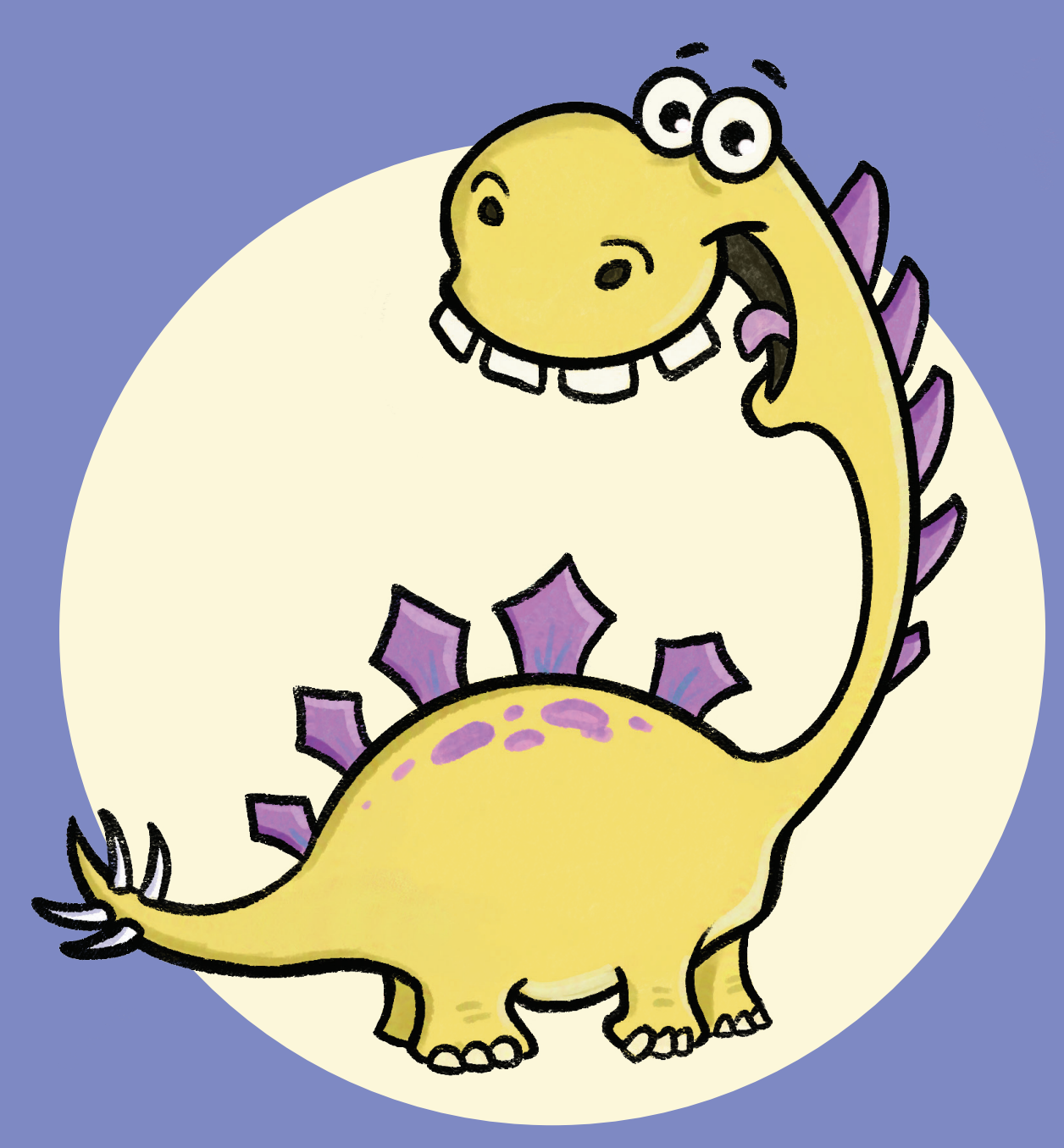

$-31-$ 


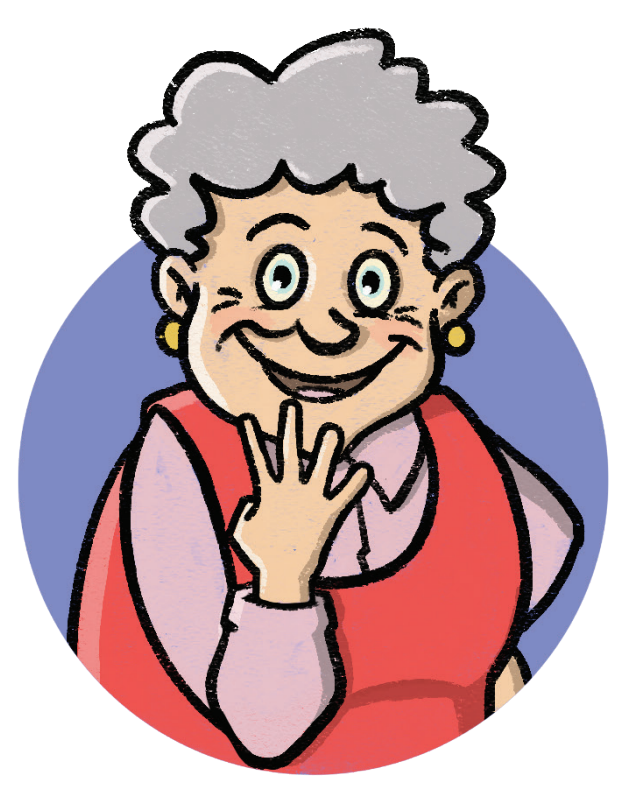

'Die richtige Antwort lautet vier. Ein Stegosaurus hat vier Stacheln an seinem Schwanz.'

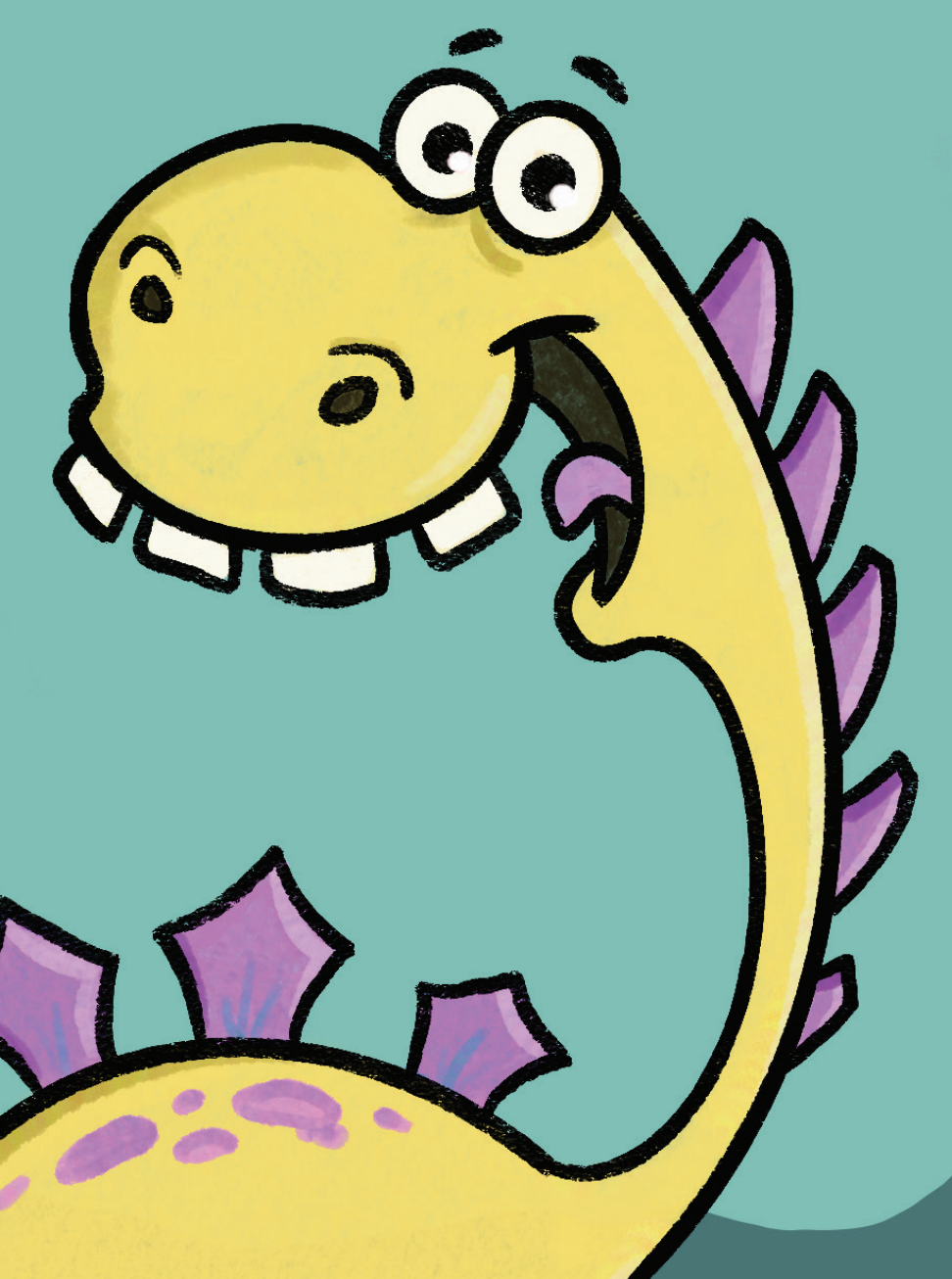


Wie gut haben Kati und Miruna die richtige Antwort vorhergesagt?
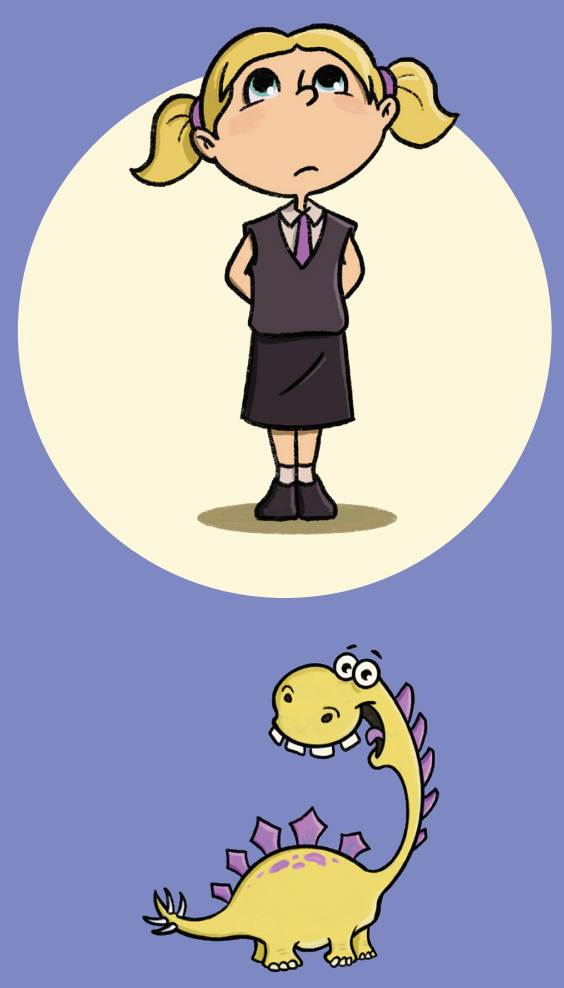

Eine von zwei ihrer Vorhersagen war richtig!

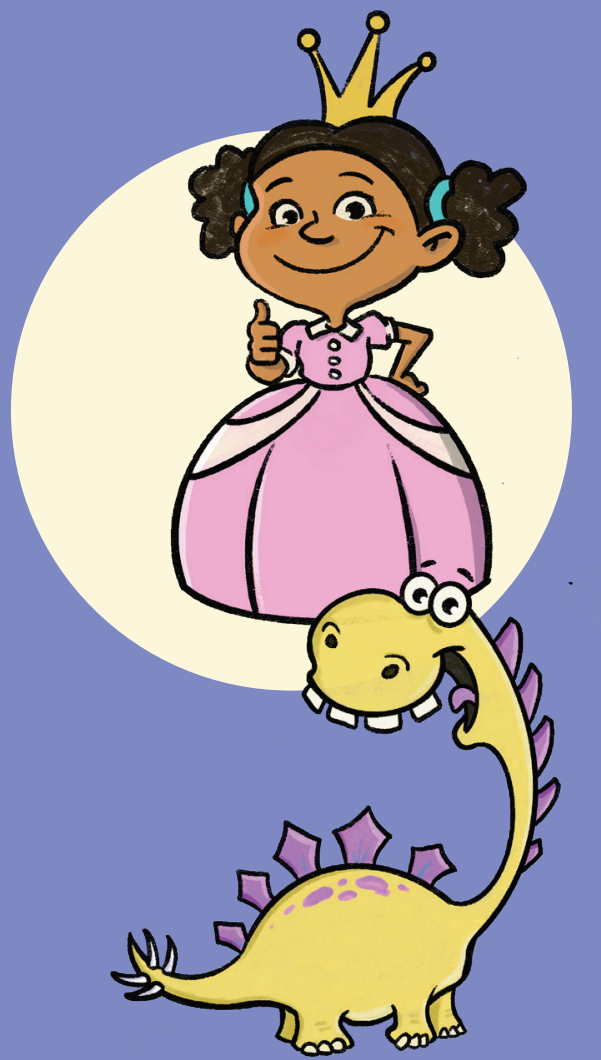

Völlig richtig!
Bei der Triceratops-Frage war Kati sechsmal besser im Vorhersagen als Miruna.
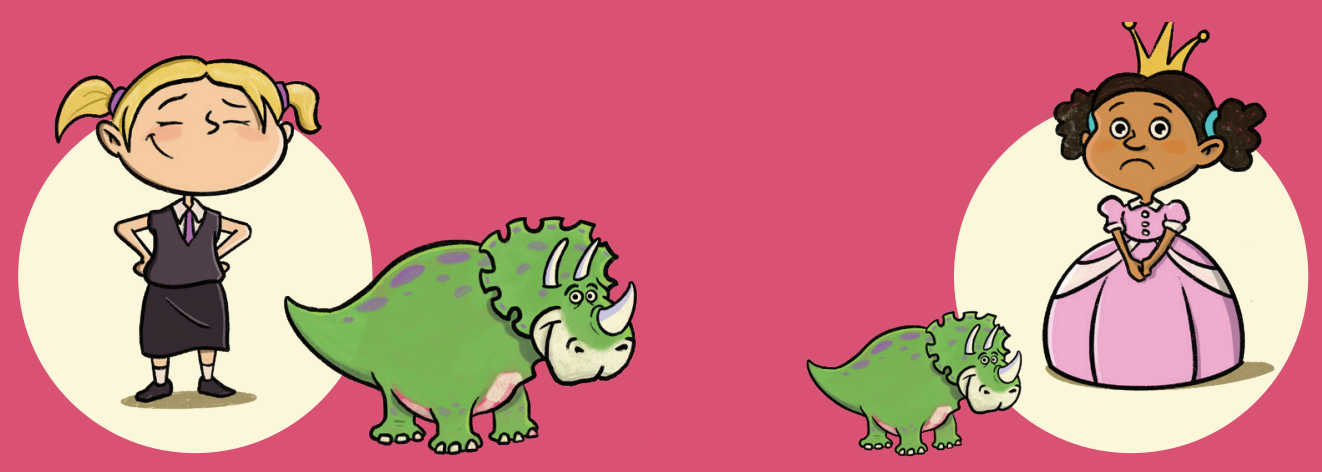

Bei der Stegosaurus-Frage war Miruna zweimal besser im Vorhersagen als Kati.

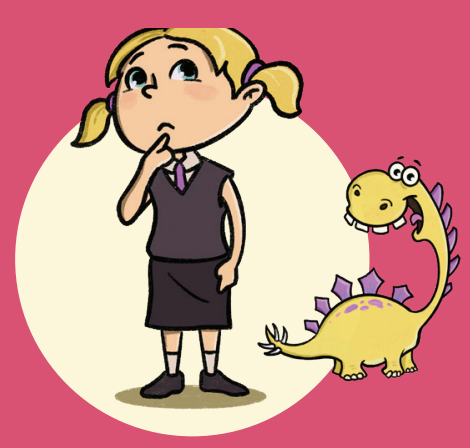


Insgesamt war Kati also 6/2 = $3 \mathrm{Mal}$ besser im Vorhersagen als Miruna. Deshalb kommt Tante Agathe nun zu dem Schluss, dass Kati dreimal so viele Kekse verdient wie Miruna.

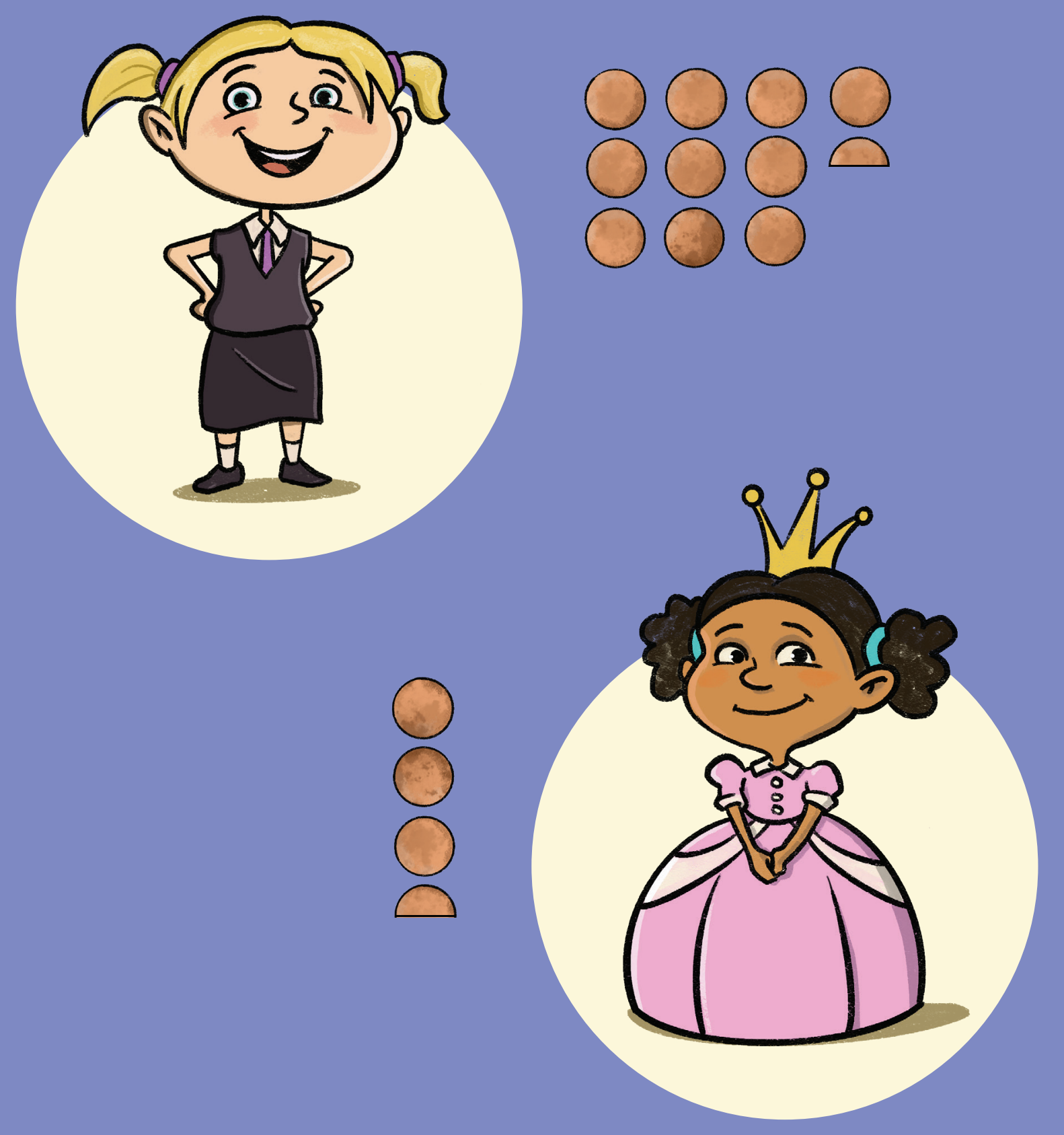




\section{Kinder, was haben wir gelernt?}

1 Ein Triceratops hat drei Hörner auf seinem Kopf.

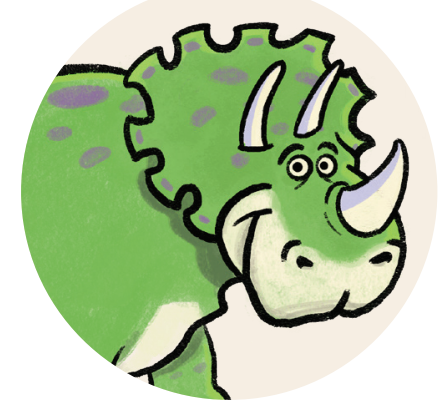

2 Ein Stegosaurus hat vier Stacheln an seinem Schwanz.

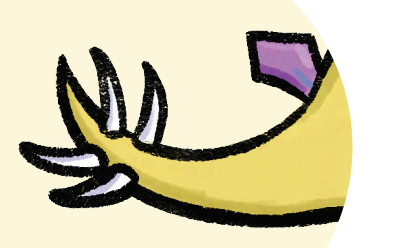

3 Kekse messen Gewissheit.
Kati hat insgesamt besser bei dem Dinosauriertest abgeschnitten als Miruna und darum glaubt Tante Agathe nun, dass Kati mehr über Dinosaurier weiß - Tante Agathe ist sich jedoch nicht völlig sicher.

Deshalb bekommt Miruna trotzdem ein paar Kekse, obwohl sie schlechter im Test abgeschnitten hat als Kati.

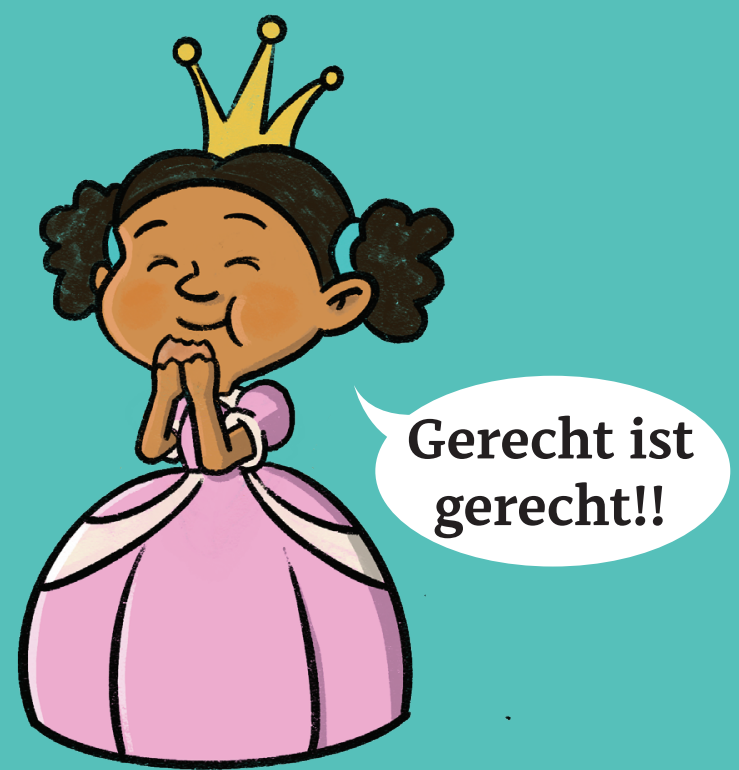


4 Im Laufe der Zeit hat sich Tante Agathes Gewissheit verändert.

Zunächst war sich Tante Agathe noch völlig unsicher, wer mehr über Dinosaurier weiß. Nachdem sie die Triceratops-Frage gestellt hatte, glaubte Tante Agathe, dass Kati wahrscheinlich am meisten wei $\beta$.

Doch nach ihrer Stegosaurus-Frage bekam Tante Agathe wieder mehr Zweifel.

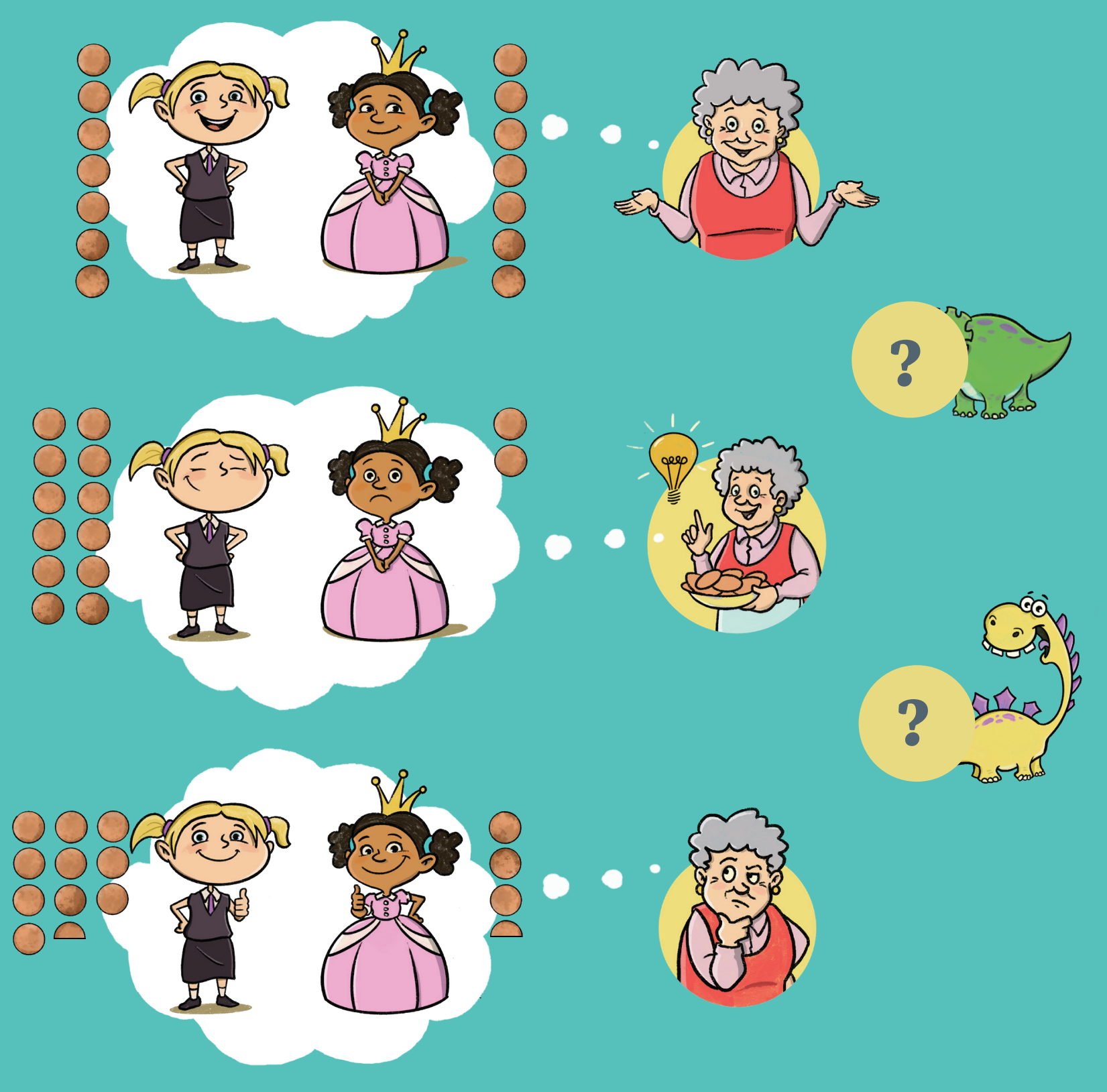

$-41$ 
5 Kati schnitt besser in der Triceratops-Frage $\mathrm{ab}$ als Miruna, aber Miruna schnitt besser in der Stegosaurus-Frage ab als Kati.

Jede der beiden war einmal besser, da es beeindruckender ist eine Antwort genau zu wissen als eine Antwort ungefähr zu wissen.

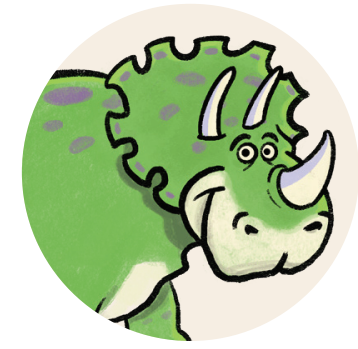

Die Antwort genau wissen

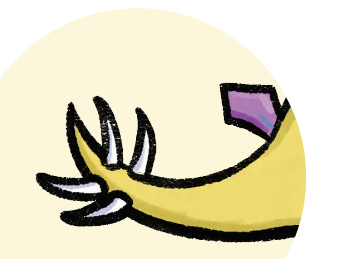

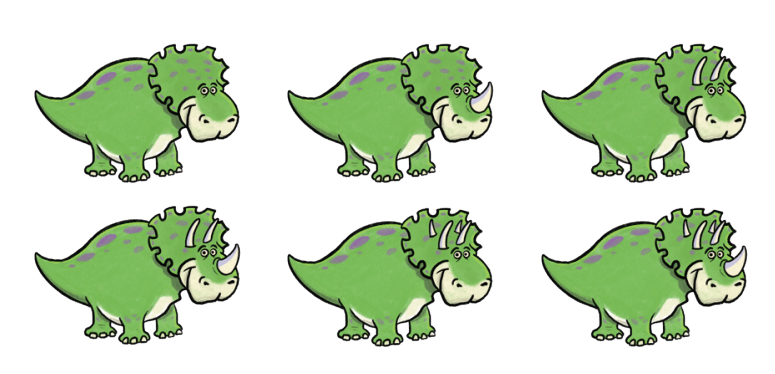

Die Antwort ungefähr wissen

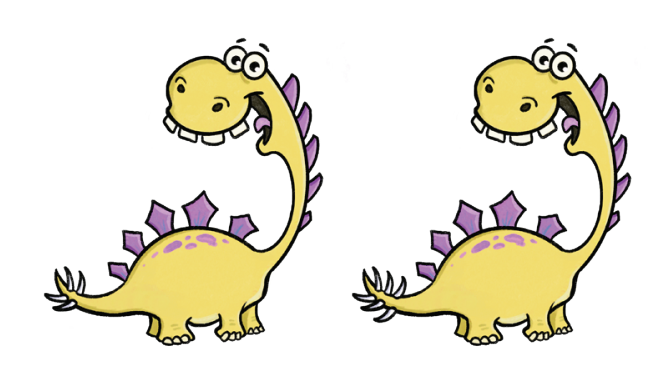

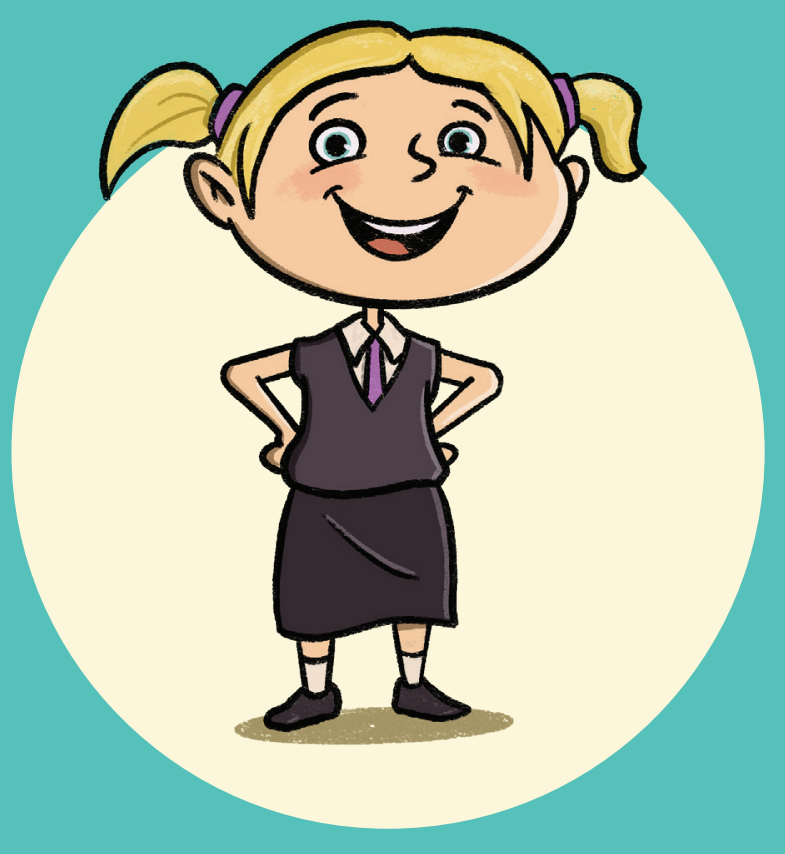




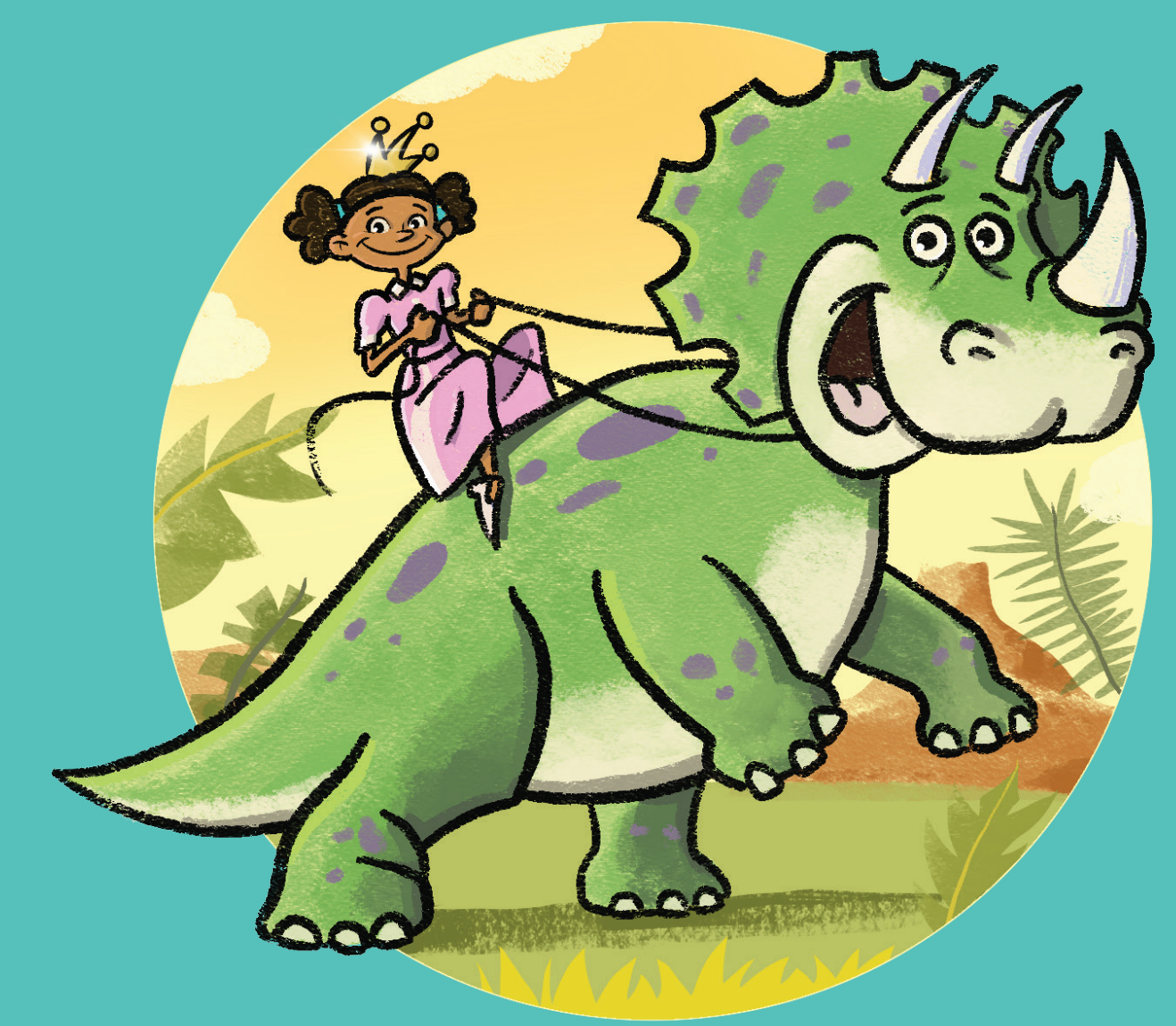

Kinder, Studierende sowie Wissenschaftlerinnen und Wissenschaftler können JASP dazu nutzen, realistischere Bayesianische Analysen durchzuführen. JASP kann man kostenlos

herunterladen unter jasp-stats.org.

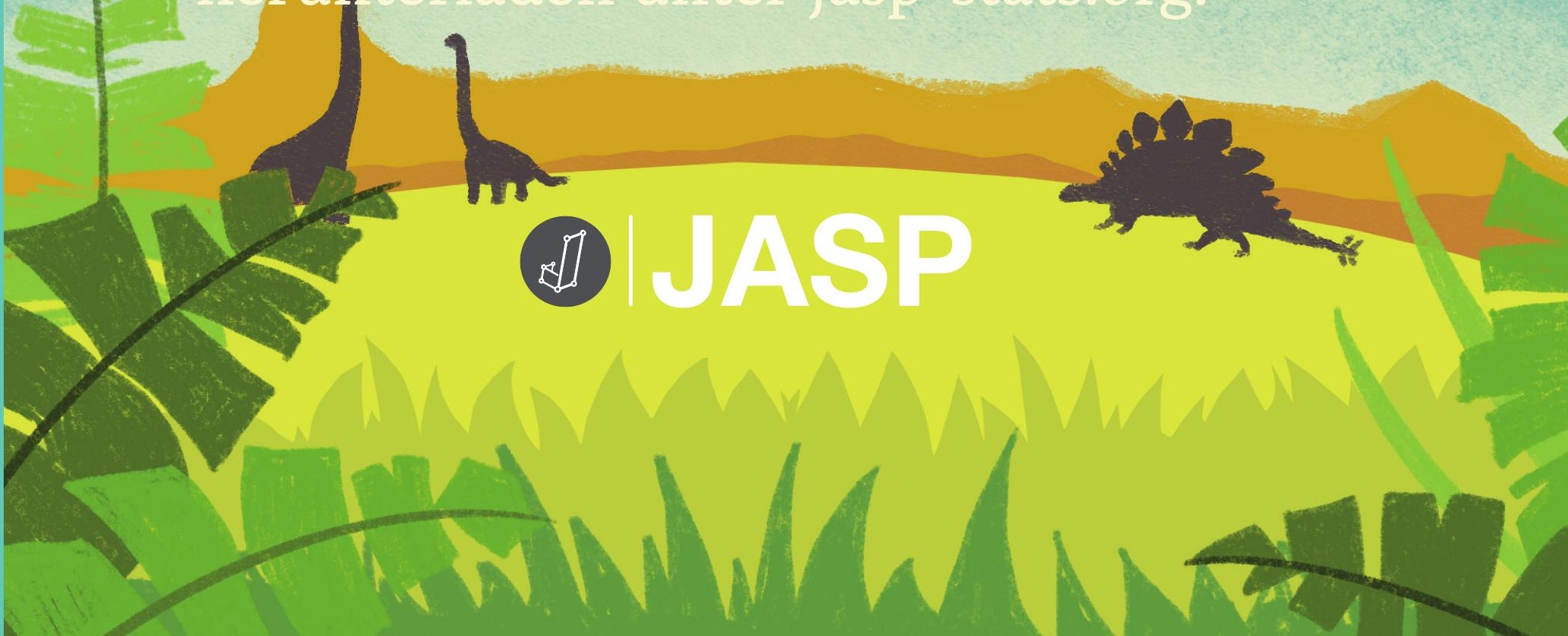




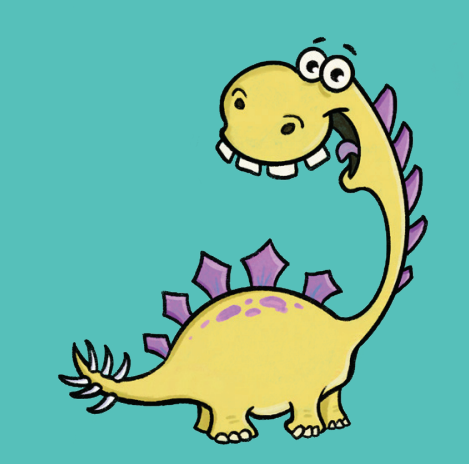

\section{Eric-Jan Wagenmakers}

Illustriert von Viktor Beekman

Graphische Gestaltung von Johan van der Woude

Übersetzt aus dem Englischen von Alexandra Sarafoglou und Angelika Stefan

๑ ) JASP | 2020 
Bayesianisches Denken ist einfach und Kinder tun es die ganze Zeit. Das Grundprinzip dieser Denkweise ist das Lernen durch Erfahrung: Hypothesen, die die Daten gut vorhersagen können, werden wahrscheinlicher, während Hypothesen, die die Daten schlecht vorhersagen können, weniger wahrscheinlich werden. Hypothese A ist beispielsweise "Um 6 Uhr morgens schlafen meine Eltern meistens noch" und Hypothese B ist "Um 6 morgens sind meine Eltern meistens schon wach". Wenn ein Kind dann um 6 Uhr morgens aufwacht und bemerkt, dass seine Eltern noch tief und fest schlafen, erhöht diese Beobachtung die Plausibilität von Hypothese A und verringert die von Hypothese B. Ganz einfach!

Sachkundigen Leserinnen und Lesern wird aufgefallen sein, dass die Titelgeschichte der Dinosaurier Hinweise liefert zu Konzepten wie Ockhams Rasiermesser, der regelgeleiteten Aktualisierung von Wissen und dem Begriff der Wahrscheinlichkeit als Grad der Gewissheit im Lichte einer bestimmten Beweislage. Statistikerinnen und Statistiker werden in der Geschichte vielleicht das "prequentielle Prinzip" von Phil Dawid wiederfinden. Kinder sind womöglich nur an den Dinosauriern interessiert.

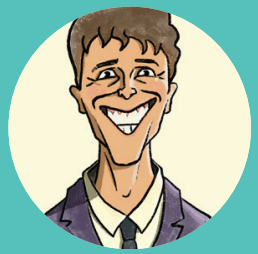

Eric-Jan Wagenmakers ist Professor im Fachbereich Psychologische Methodenlehre an der Universität von Amsterdam. Er ist außerdem der Gründer von JASP (jasp-stats.org), einem kostenlosen und nutzerfreundlichen Softwareprogramm, mit dem man Bayesianische und nicht-Bayesianische statistische Analysen durchführen kann.

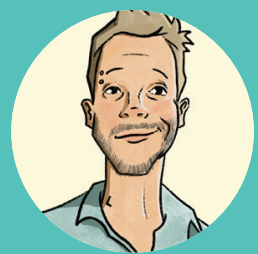

Viktor Beekman ist ein Designer und Illustrator und lebt in der niederländischen Stadt Hilversum. Mehr von seiner Arbeit gibt es auf seiner Instagram-Seite zu sehen: @viktordepictor 